\title{
Development of a Catalytic Coating for a Shuttle Flight Experiment
}

\author{
David A. Stewart, ${ }^{*}$ Tahir Gökçen, ${ }^{\dagger}$ Steven E. Sepka, ${ }^{\ddagger}$ Daniel B. Leiser, ${ }^{\S}$ and Marc D. Rezin ${ }^{* *}$ \\ NASA Ames Research Center, Moffett Field, CA 94035
}

\begin{abstract}
A spray-on coating was developed for use on the shuttle wing tiles to obtain data that could be correlated with computational fluid dynamics (CFD) solutions to better understand the effect of chemical heating on a fore-body heat shield having a turbulent boundary layer during planetary entry at hypersonic speed. The selection of a spray-on coating was conducted in two Phases 1) screening tests to select the catalytic coating formulation and 2) surface property determination using both arc-jet and side-arm facilities at NASA Ames Research Center. Comparison of the predicted surface temperature profile over a flat-plate with measured values obtained during arc-jet exposure (Phase I study) was used to validate the surface properties obtained during Phase II.
\end{abstract}

\section{Introduction}

$\mathrm{T}$ HE effect of surface catalysis on heating to a vehicle entering the Earth atmosphere at hypersonic speed was first demonstrated during the catalytic surface effects Orbiter flight experiments conducted in the early 1980s. ${ }^{1-5}$ These experiments, used a cobalt iron chromium oxide spinel, designated as C-742, mixed with a Polyvinyl acetate (PVA) binder. It was sprayed on selected tiles over the lower surface of the fuselage and wing of the Orbiter. Surface temperature measurements were taken during the portion of the trajectory where the boundary layer was laminar $\left(\mathbf{M}_{\infty}>10\right)$. This coating was referred to as CC-1. The present boundary layer transition (BLT) experiment will investigate the effect of a high catalytic efficiency surface on heating during Earth entry with a turbulent boundary layer at Mach numbers near 18 using a similar spray-on coating to the $\mathrm{CC}-1$. Because the $\mathrm{C}-742$ spinel is no longer available, candidate formulations with similar spinel structure and surface properties to the $\mathrm{CC}-1$ coating were developed for the BLT flight experiment.

The two coatings evaluated as a replacement for the CC-1 coating included a mixture of two spinels (15B) and a formulation of reacted oxides (15E). Coating $15 \mathrm{~B}$ was formulated by directly mixing a small amount of glass frit with a $\mathrm{CoCr}_{2} \mathrm{O}_{4}$ spinel and a $\mathrm{CoFe}_{2} \mathrm{O}_{4}$ spinel. Coating $15 \mathrm{E}$ was formulated by first reacting the appropriate amount of chromium, iron, and cobalt oxides to create a single spinel having a similar structure to the C-742; then a small amount of silicon dioxide (Quartz frit) was mixed with the spinel powder. Polyvinyl acetate (PVA) was used as the binder for both coatings.

\section{Test Facilities}

\section{A. Arc-jet Facility}

The arc-jet tests were conducted in the Aerodynamic Heating Facility (AHF). ${ }^{6}$ A sketch of the AHF is shown in Figure 1a. The facility uses a constricted arc-heater to provide high-energy dissociated hypersonic flow over a test model positioned downstream of the 8 degree half-angle conical nozzle. A large boiler plant is used to maintain the pressure ratio between the arc-heater and test-section required for steady-state hypersonic flow.

\footnotetext{
* Senior Research Scientist, Thermal Protection Materials and Systems Branch, MS 234-1

† Senior Research Scientist, ELORET Corporation, MS 230-2, Senior Member AIAA

* Senior Research Scientist, ELORET Corporation

${ }^{\S}$ Senior Research Scientist, Thermal Protection Materials and Systems Branch

*** Aerospace Engineer, Thermal Protection Materials and Systems Branch

$$
1
$$
}

American Institute of Aeronautics and Astronautics 


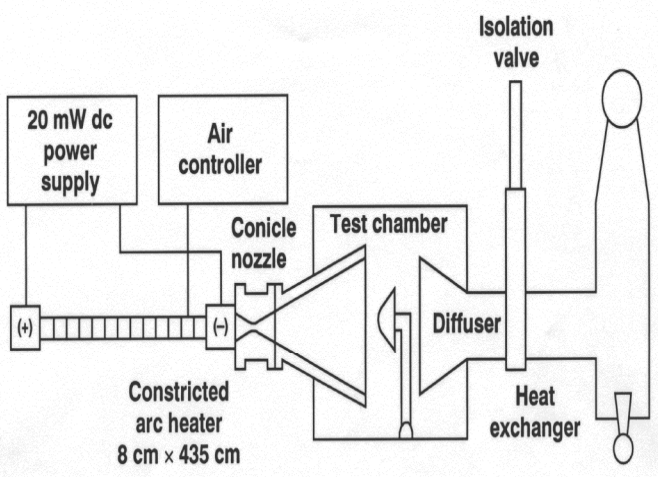

(a) Aerodynamic Heating Facility

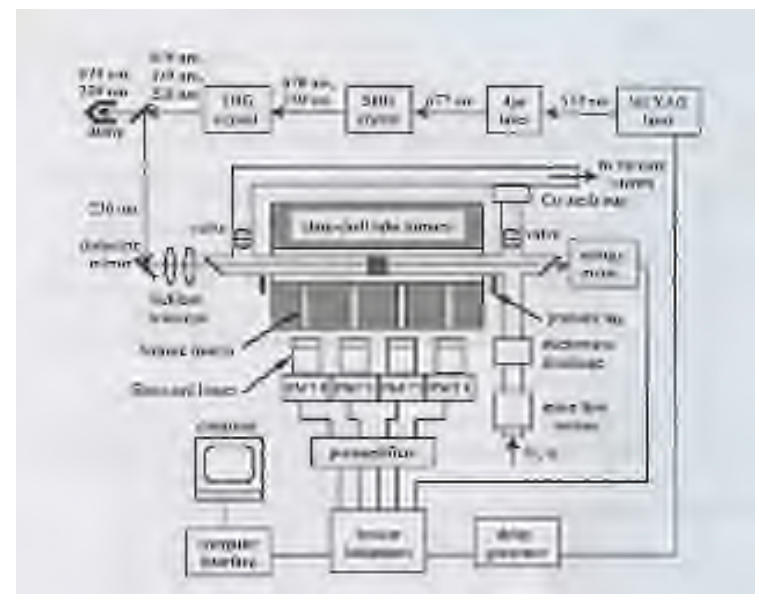

(b) Side-Arm Reactor

\section{Figure 1. Schematics of Test Facilities.}

Either nitrogen or air can be easily used as the test gas without altering the heater hardware. This permits measurements of heat flux and temperature to be taken in consecutive order from a test model. Surface conditions on the test model are varied by changing the 1) exit diameter of the nozzle, 2) reservoir pressure, and/or 3) electrical power dissipated in the heater.

The geometric area ratio (nozzle exit to throat) of the facility can be varied from 64 to 400 . Heater pressure can be varied from $0.68 \mathrm{~atm}$ to roughly $5.5 \mathrm{~atm}$ and the maximum power dissipated in the heater can be increased up to $20 \mathrm{MW}$. Stagnation point enthalpy was determined using a facility system energy balance approach. ${ }^{7}$ It requires that the predicted enthalpy is compatible with all measured flow properties during each arc-jet test.

A pyrometer, radiometer, and copper hemisphere were used to measure surface temperature, heat flux and pressure during each test.

\section{B. Side-Arm Reactor}

Figure $1 \mathrm{~b}$ is a schematic of the side-arm-reactor used to obtain both the atom recombination coefficient for nitrogen and oxygen. The data were obtained using a three-section diffusion tube (short sample of test material (L/D $<1)$ positioned between two sections of quartz tube) that was placed at the center of the clamshell tube furnace. This furnace enables the coefficients to be calculated from room temperature to $1200 \mathrm{~K}$. The test gas is dissociated using a microwave discharge upstream of the side-arm diffusion tube and the coefficients are calculated using measurements from laser-induced fluorescence (LIF) diagnostic techniques to obtain the specie concentration profile along the tube centerline. ${ }^{8-9}$ The profile is obtained from the atom fluorescence measured through quartz lined optical access ports using four photomultiplier (PMT) equally spaced along the furnace.

\section{Test Articles}

Test articles used during this study are shown in Figure 2. During Phase I, a disc-shaped test article coated with the reaction-cured-glass (RCG) over the front surface and approximately 1-inch down its sides, was installed into a flat-plate test fixture, Figure 2a. The fixture was made from a high-density fibrous insulation that was also coated with RCG glass. It had a nose radius of $2.2 \mathrm{~cm}(0.875 \mathrm{in})$, length of $16.5 \mathrm{~cm}(6.5 \mathrm{in})$, and width of $12.7 \mathrm{~cm}(5.0 \mathrm{in})$. Included in the figure is a sketch of the disk that was installed in the flat plate. It had two type-R thermocouples installed symmetric to the center of the disk. The catalytic coatings were applied to the downstream half of the top surface of the disk. During Phase II, the test articles used were a blunt $5^{\circ}$ cone and a flat-faced cylinder, Figure $2 \mathrm{~b}$. During these tests, the catalytic coatings were applied over the front surface of the test article. Both Phase I and Phase II tests were conducted in the AHF using the 24-inch nozzle. 


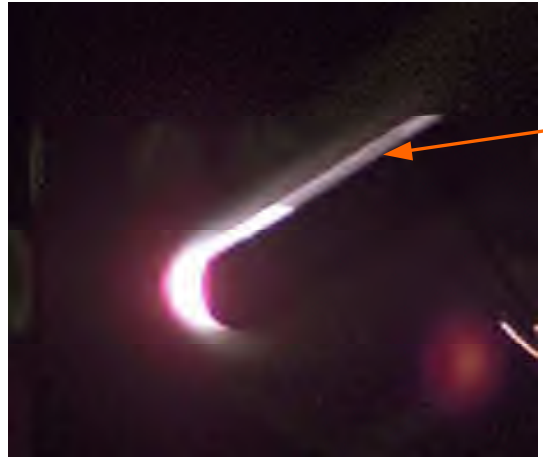

(a) Flat-plate

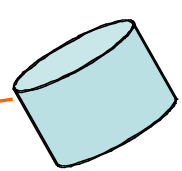

(b) Flat-face cylinder

Figure 2. Arc-jet test articles used during Phase I and Phase II studies.

\section{Experiments}

The study was conducted in two Phases: 1) Screening tests were conducted to select one of two candidate coatings (15B and 15E) for use as the catalytic coating for the BLT experiment. These tests were conducted using the flat plate at an angle-of-attack of $30^{\circ}$, Figure 2a. One of the test articles used to obtain the surface properties of the coating was the flat-faced cylinder shown in Figure 2b. Selection of the coating was based on the material stability during a nine-minute arc jet exposure at a surface temperature of $1589 \mathrm{~K}\left(2400{ }^{\circ} \mathrm{F}\right)$. Data used in the selection were spectral reflectance, and surface chemistry measurements that were taken before and after arc jet exposure. Also, photographs and scanning electron microphotographs (SEMs) of the samples were obtained before and after arc-jet exposure. Room temperature spectral reflectance measurements were made using a BIO-RAD model FTS 40 (wavelength range 0.25 microns to 2.5 microns) and Perkin Elmer model 310 (wavelength range 2.5 microns to 18 microns) spectrophotometers. Pre and post-test surface chemistry was determined using x-ray fluorescence elemental analyses. In addition to the above data, atom recombination coefficients for both oxygen and nitrogen were calculated using arc jet and side-arm-reactor experiments for the selected coating.

\section{Results and Discussion}

The arc-jet test data taken during Phase I and II are summarized in Tables 1 and 2.

Table 1. Summary of Phase I test results.

Coating Performance

\begin{tabular}{|c|c|c|c|c|c|c|c|}
\hline $\begin{array}{l}\text { Run } \\
\text { No. }\end{array}$ & Sample & Coating & $\begin{array}{l}P_{0} \\
\text { atm. }\end{array}$ & $\begin{array}{c}H_{\infty} \\
\mathrm{MJ} / \mathrm{kg}\end{array}$ & $\begin{array}{c}\text { Twesc } \\
\text { Meas. } \\
K\end{array}$ & $\begin{array}{c}\text { Tyes } \\
\text { Galc. } \\
K\end{array}$ & $\begin{array}{c}T_{\text {wat }} \\
\text { Meas. } \\
K \\
\end{array}$ \\
\hline 1 & 3608 & $15 E$ & 0.012 & 13.5 & 1244 & 1228 & 1594 \\
\hline 2 & 3610 & $15 B$ & 0.013 & 13.5 & 1250 & 1228 & 1589 \\
\hline
\end{tabular}

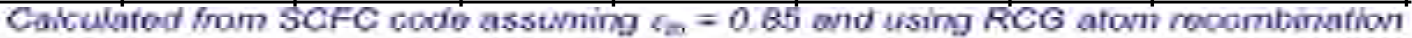
coefficients for oxygen and nirogen.

Free-stream Properties

\begin{tabular}{|c|c|c|c|c|c|}
\hline $\begin{array}{c}\mathrm{P}_{\mathrm{CH}} \\
\mathrm{atm} .\end{array}$ & $\mathrm{M}_{\mathrm{f}}$ & $M_{-}$ & $\begin{array}{c}\mathrm{T}_{-} \\
K\end{array}$ & $\gamma_{-}$ & $\begin{array}{c}\mathrm{U}_{-} \\
\mathrm{m} / \mathrm{s}\end{array}$ \\
\hline 1.7 & 1.8 & 8.03 & 608 & 1.37 & 4148 \\
\hline
\end{tabular}

Free-stream Flow Chemistry

(mole fraction)

\begin{tabular}{|c|c|c|c|c|c|}
\hline $\mathrm{N}$ & $\mathrm{N}_{\mathrm{z}}$ & $\mathrm{O}$ & $\mathrm{O}_{2}$ & $\mathrm{NO}$ & $\mathrm{Ar}$ \\
\hline 0.122 & 0.41 & 0.247 & $\ldots .004$ & 0.22 & 0.22 \\
\hline
\end{tabular}


Table 2. Summary of Phase II test results: surface characterization of coating CC-2.

\begin{tabular}{|c|c|c|c|c|c|c|c|}
\hline \multicolumn{8}{|c|}{ Coating Performance } \\
\hline $\begin{array}{l}\text { Run } \\
\text { No. }\end{array}$ & Gas & $\begin{array}{l}P_{\text {एक }} \\
\text { atm }\end{array}$ & $\begin{array}{l}P_{0} \\
\text { atm. }\end{array}$ & $\begin{array}{c}\text { Enthalpy } \\
\text { MJ/kg }\end{array}$ & $\begin{array}{l}T_{\text {wi ca-z }} \\
\text { Meas. } \\
K \\
K\end{array}$ & $\begin{array}{c}T_{\text {wned }} \\
\text { Calc. } \\
k\end{array}$ & Sample \\
\hline \multirow[t]{3}{*}{$2-5$} & Air & 0.78 & 0.006 & 13.02 & 1361 & 1356 & $\overline{\mathrm{RCG}}$ \\
\hline & \multicolumn{4}{|c|}{$\mathrm{e}_{\mathrm{th}}=0.74$, Coefficients, $\gamma_{\mathrm{N}}=0.5, \gamma_{\mathrm{o}}=0.44$} & 1564 & 1561 & $\overline{F F}(4-1)$ \\
\hline & \multicolumn{4}{|c|}{$\mathrm{e}_{\mathrm{th}}=0.72$, Coefficients, $\gamma_{\mathrm{N}}=05, \gamma_{\mathrm{U}}=0.5$} & 1617 & 1622 & BC 3614 \\
\hline \multirow[t]{3}{*}{$3-4$} & Nitrogen & 0.78 & 0.006 & 15.1 & 1378 & 1394 & RCG \\
\hline & \multicolumn{4}{|c|}{ Coeflicients, $\gamma_{N}=0.5$} & 1611 & 1617 & FF (4-3) \\
\hline & \multicolumn{4}{|c|}{ Coefficients, $\gamma_{\mathrm{N}}=0.59$} & 1689 & 1700 & BC 3615 \\
\hline 5 & Air & 0.82 & 0.007 & 14.53 & 1700 & 1689 & BC LI900 \\
\hline
\end{tabular}

Free-stream Properties

\begin{tabular}{|c|c|c|c|c|c|}
\hline Run No. & $\mathrm{M}_{\mathrm{f}}$ & $\mathrm{M}_{\infty}$ & $\begin{array}{c}\mathrm{T}_{\infty} \\
\mathrm{K}\end{array}$ & $\gamma_{\infty}$ & $\begin{array}{c}\mathrm{U}_{\infty} \\
\mathrm{m} / \mathrm{s}\end{array}$ \\
\hline $2-5$ & 1.2 & 8.8 & 441 & 1.3 & 3853 \\
\hline $3-4$ & 1.1 & 8.56 & 484 & 1.35 & 3993 \\
\hline 5 & 1.2 & 8.93 & 429 & 1.34 & 3956 \\
\hline
\end{tabular}

Free-stream Flow Chemistry (mole fraction)

\begin{tabular}{|c|c|c|c|c|c|c|}
\hline Runs No. & $\mathrm{N}$ & $\mathrm{N}_{2}$ & $\mathrm{O}$ & $\mathrm{O}_{2}$ & $\mathrm{NO}$ & $\mathrm{Ar}$ \\
\hline $2-5$ & 0.16 & 0.40 & 0.25 & ---- & 0.004 & 0.186 \\
\hline $3-4$ & 0.37 & 0.44 & $\mathrm{~N} / \mathrm{A}$ & $\mathrm{N} / \mathrm{A}$ & $\mathrm{N} / \mathrm{A}$ & 0.19 \\
\hline 5 & 0.21 & 0.36 & 0.24 & ---- & 0.003 & 0.18 \\
\hline
\end{tabular}

The screening tests (Table 1) were conducted at a total enthalpy of $13.5 \mathrm{MJ} / \mathrm{kg}$ (5800 Btu/lbm), impact pressure of $0.012 \mathrm{~atm}$. The dissociated species in the shock layer is given in terms of mole fraction, the oxygen was fully dissociated (0.247) and the nitrogen was partially dissociated (0.122). In addition, roughly 0.22-mole fraction of argon was present. The measured temperature on the upstream RCG-coated surface of the disk was $1244 \mathrm{~K}$ (1780 $\left.{ }^{\circ} \mathrm{F}\right)$ and on the downstream catalytic coated surface of the disk it was $1589 \mathrm{~K}\left(2400{ }^{\circ} \mathrm{F}\right)$. The measured surface temperature on the RCG-coated portion of the flat-plate test article was $1244 \mathrm{~K}\left(1775^{\circ} \mathrm{F}\right)$. The calculated value was predicted using RCG atom recombination coefficients, the SCFC code, and assuming a Lee's heating distribution from the stagnation point to the location where the measurement was taken on the disk..$^{10,11}$

The Phase II tests were conducted using both nitrogen and air at a free-stream Mach number over 8.0. The mole fraction of the dissociated nitrogen was 0.37 in the nitrogen environment and 0.16 to 0.21 in the air environments with the oxygen fully dissociated (0.25). During these tests, the total enthalpy was $15.1 \mathrm{MJ} / \mathrm{kg}(6500 \mathrm{Btu} / \mathrm{lbm})$ for the nitrogen test gas and ranged from $13.0 \mathrm{MJ} / \mathrm{kg}(5600 \mathrm{Btu} / \mathrm{lbm})$ to $14.5 \mathrm{MJ} / \mathrm{kg}(6250 \mathrm{Btu} / \mathrm{lbm})$ for air. The stagnation point pressure was roughly $0.006 \mathrm{~atm}$ during both test environments, and the surface temperature on the test articles ranged from $1361 \mathrm{~K}\left(1990^{\circ} \mathrm{F}\right)$ to $1700 \mathrm{~K}\left(2600{ }^{\circ} \mathrm{F}\right)$. A LI-900 test article with the CC-2 coating was exposed to the hypersonic stream for 3 minutes at $1700 \mathrm{~K}\left(2600^{\circ} \mathrm{F}\right)$ and showed no recession after exposure. Table II lists the calculated atom recombination coefficients for both nitrogen and oxygen obtained using the test data and the SCFC code. The coefficients for oxygen were 0.44 at $1561 \mathrm{~K}\left(\mathrm{~T}_{\mathrm{W}}=2350{ }^{\circ} \mathrm{F}\right)$ and 0.5 at $1617 \mathrm{~K}\left(\mathrm{~T}_{\mathrm{W}}=2450{ }^{\circ} \mathrm{F}\right)$. Coefficients for nitrogen were 0.5 at $1617 \mathrm{~K}\left(\mathrm{~T}_{\mathrm{W}}=2450{ }^{\circ} \mathrm{F}\right)$ and 0.59 at $1689 \mathrm{~K}\left(\mathrm{~T}_{\mathrm{W}}=2580{ }^{\circ} \mathrm{F}\right)$. Within this temperature range, the average total hemispherical emittance ranged from 0.72 to 0.74 based on the arc-jet data. 


\section{A.Phase I: Screening Tests}

15B (spinel mixtures)

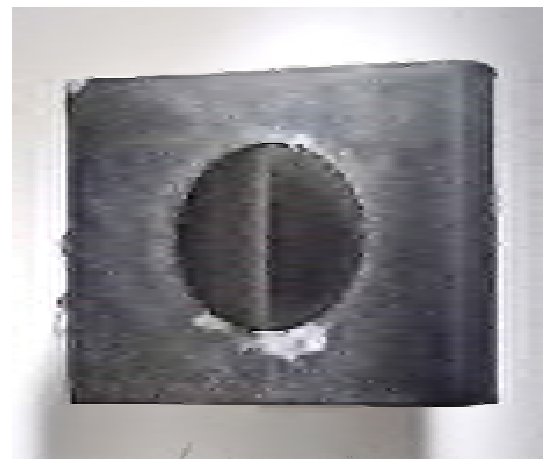

15E (reacted oxides)

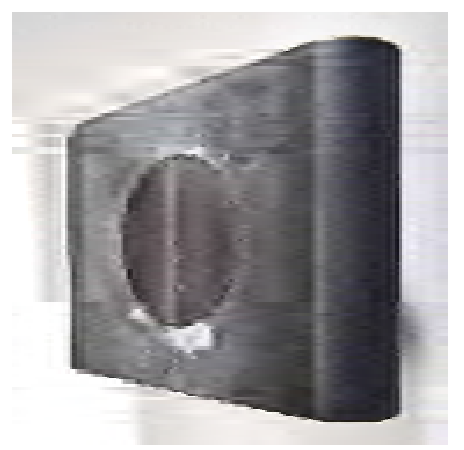

a) Photographs of the test articles after a nine minute exposure, $T_{W}=1589 \mathrm{~K}$.
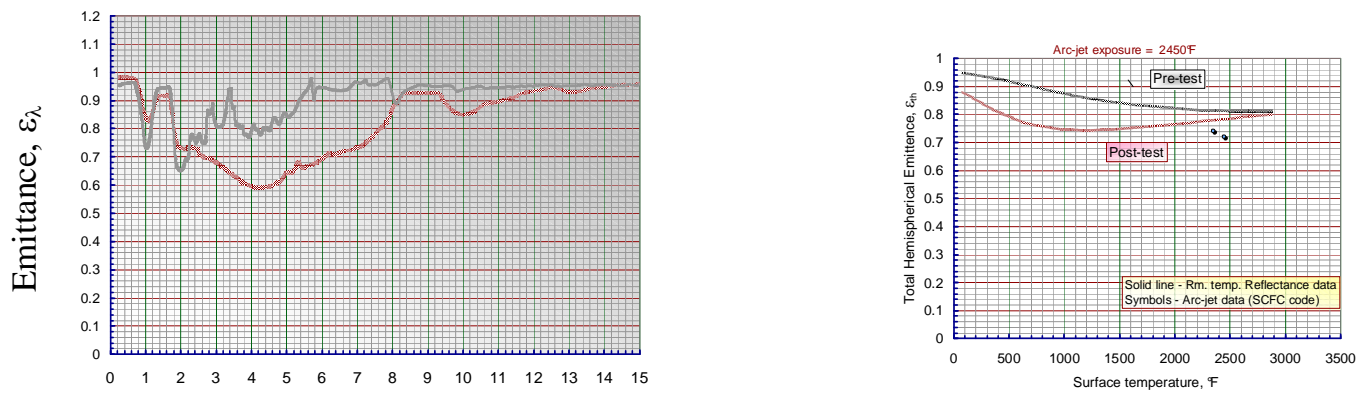

Wavelength, $\lambda$, microns

\section{b) Spectral hemispherical emittance.}

Figure 3. Effect of arc-jet exposure on surface properties of the candidate coatings.

The photographs show that the surface color of $15 \mathrm{E}$ and 15B are closer to the RCG coating after arc-jet exposure. Comparison of pre and post-test emittance for both coatings are shown in Figure 3b. The emittance plotted was obtained from spectral hemispherical reflectance data applying ohm's law, which assumes that the coating is opaque. The emittance decreased between roughly 2.5 and 8 -microns after arc-jet exposure. The decrease in emittance is attributed to the loss of the PVA during the initial portion of the exposure. 


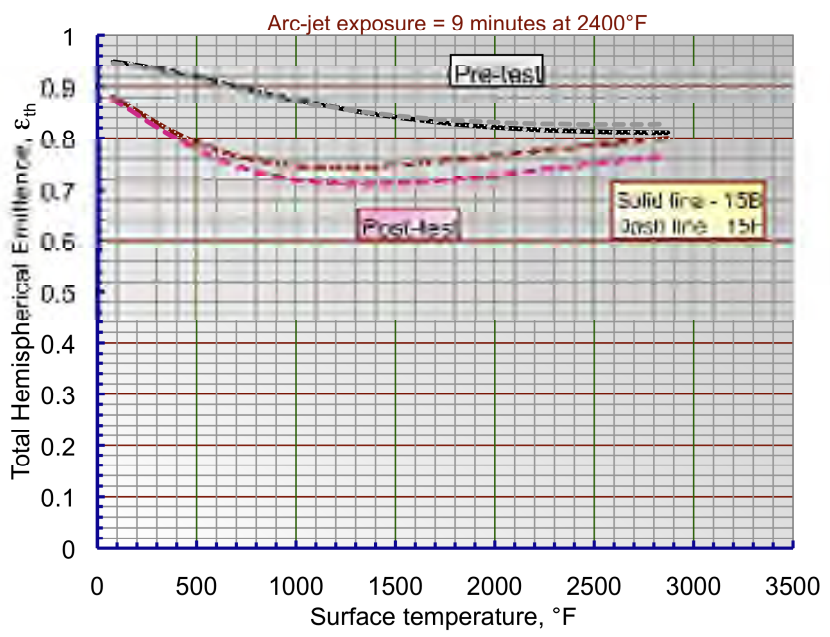

Figure 4. Effect of arc-jet exposure on emittance after nine minutes at $T_{W}=1589 \mathrm{~K}\left(2400^{\circ} \mathrm{F}\right)$.

Total hemispherical emittance is plotted for both coatings as function of temperature in Figure 4

The total hemispherical emittance was calculated from the spectral emittance values (Figure 4) by integrating between appropriate wavelengths. Pre-test values show close similarity between the two, however post-test values show that $15 \mathrm{E}$ is slightly lower than $15 \mathrm{~B}$ after arc-jet exposure.

Changes in morphology and surface chemistry of the two coatings were compared using Scanning Electron Microphotographs (SEM) and elemental analysis (X-Ray Fluorescence Analysis), as shown in Figures 5-6. These data indicted that the coating remained on the surface after arc-jet exposure (Note change in magnification between pre- and post-test data). The elemental analysis is plotted using an intensity normalized by the value for silica, because it is stable at this surface temperature. Data taken from $15 \mathrm{E}$ and $15 \mathrm{~B}$ show the expected loss of carbon (removal of PVA binder). In addition, the data indicate the loss of all three oxides from 15E. Data taken from 15B show little change in the relative intensity of the elements, which suggests that it remained chemically stable during the exposure to the dissociated hypersonic flow. 
Pre test

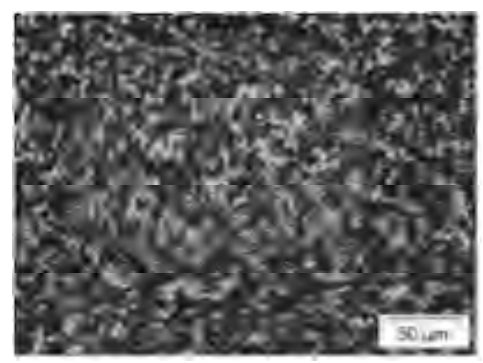

a) SEM

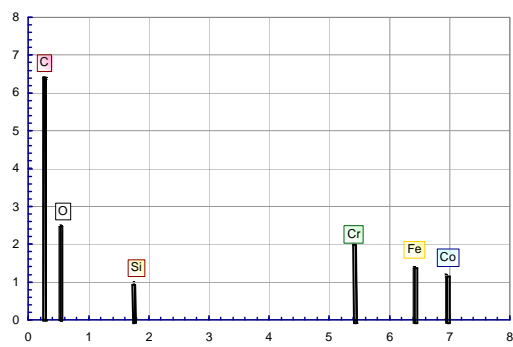

Post-test

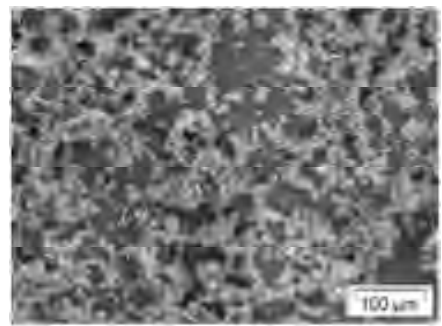

$100 \mu \mathrm{m}$

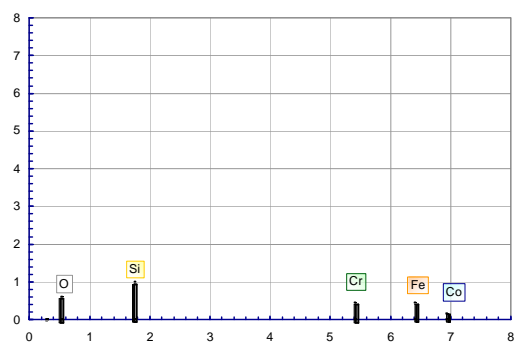

Energy, $\mathrm{KeV}$

Figure 5. SEM and X-ray florescence analysis of the $15 \mathrm{E}$ coating.

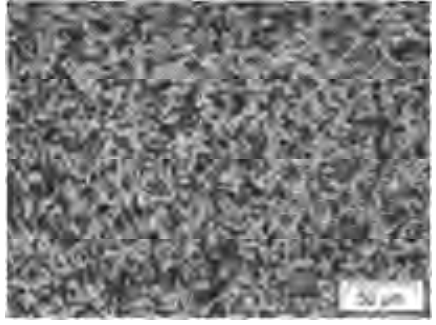

a) SEM

$50 \mu \mathrm{m}-\cdot-\cdot$

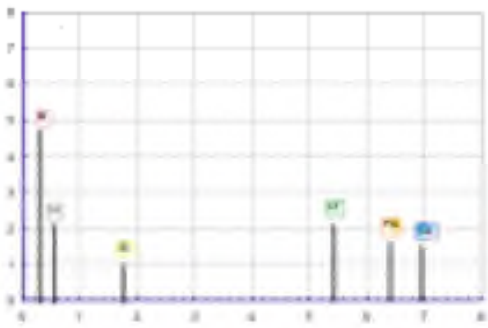

Energy, $\mathrm{KeV}$

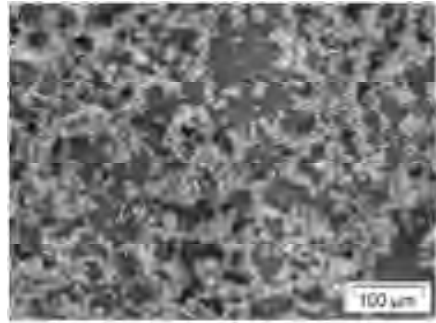

$100 \mu \mathrm{m}-\cdot-\cdot-$

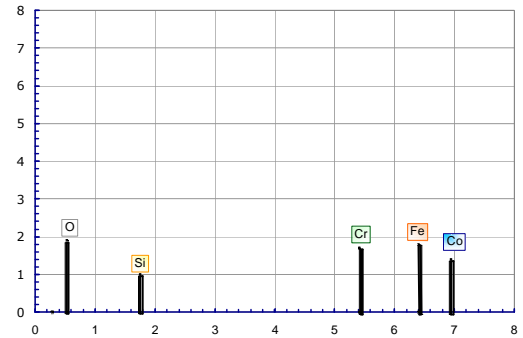

b) Elemental analysis.

Figure 6. SEM and X-ray florescence analysis of the 15B coating. 
From the screening tests 15B (spinel mixtures) was chosen was the coating for the flight experiment because it was more chemically stable during exposure to the high-energy hypersonic arc jet flow. This coating was renamed CC-2 and is referred as such throughout the Phase II study and subsequent documentation (specifications, and so forth).

\section{B. Phase II: Surface Properties}

Figures 7 shows pre- and post-test photographs of the test article used in the Phase II study. Included in Figure 7 is a photograph of the RCG reference model. The post-test photographs of the CC-2 coating were taken after a 3minute exposure at a surface temperature of $1617 \mathrm{~K}\left(2450^{\circ} \mathrm{F}\right)$ to the hypersonic air test environment. These post-test photographs show that CC-2 coating appears to be closer in color to the RCG reference model.

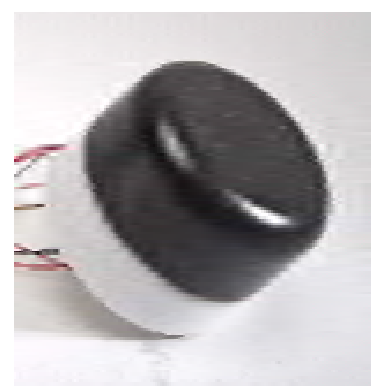

a) RCG reference

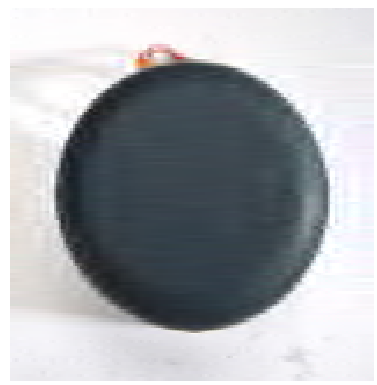

b) Pre-test

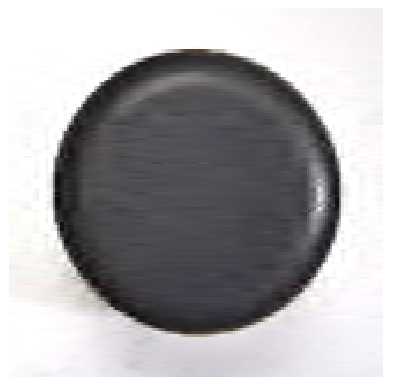

c) Post-test, $T_{W}=1617 \mathrm{~K}$

Figure 7. Effect of arc-jet exposure on $\mathrm{CC}-2$ coated blunt $5^{\circ}$ cone.

The color change is attributed to the loss of PVA from the surface of the test article.

Comparison of temperature-time histories of the CC-2 and RCG coated test articles obtained during runs 2 (air) and 4 (nitrogen) are shown in Figure 8. These data show that the temperature of the CC- 2 coating reaches a steadystate condition during the test in air, but it does not quite reach a steady-state condition during the exposure in nitrogen. The temperature data indicates a slightly higher difference between the RCG and CC- 2 coated samples in nitrogen $\left(500^{\circ} \mathrm{F}\right)$ than in air $\left(400{ }^{\circ} \mathrm{F}\right)$.
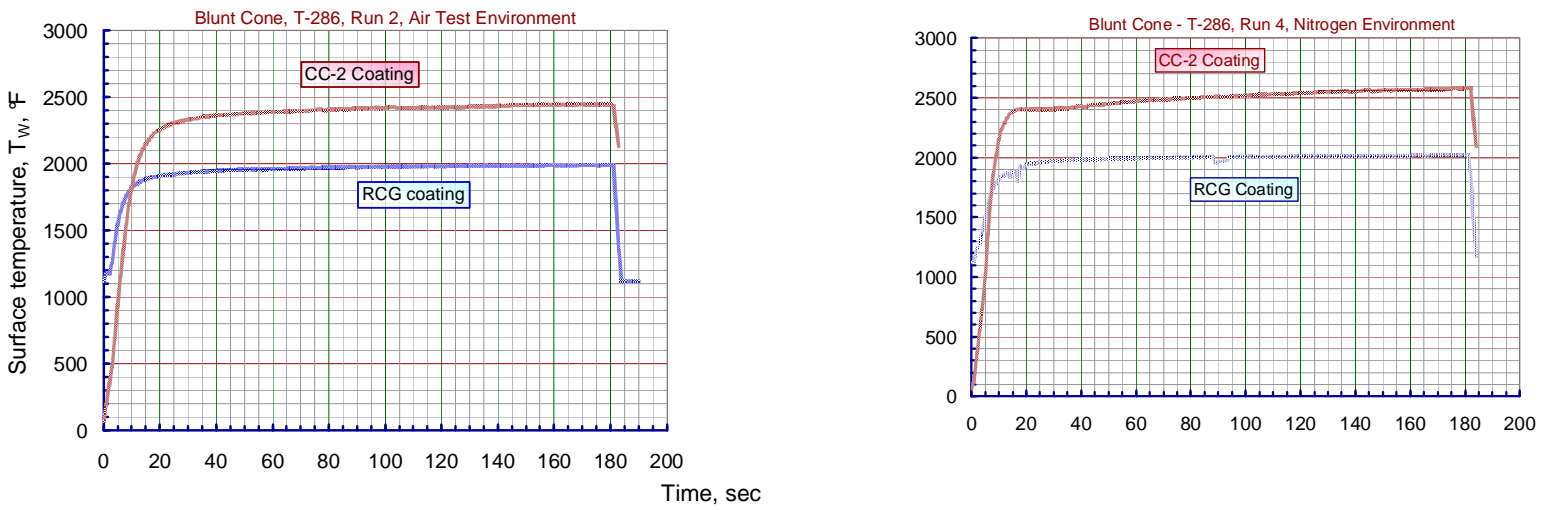

Figure 8. Temperature-time history of RCG and CC-2 coated surface during arc-jet exposure.

Pre and post-test SEMs and $\mathrm{x}$-ray fluorescence analysis suggest that after exposure at $1617 \mathrm{~K}\left(2450{ }^{\circ} \mathrm{F}\right)$ in the air test environment, the coating remained intact but became slightly oxidized. 
Pre-test

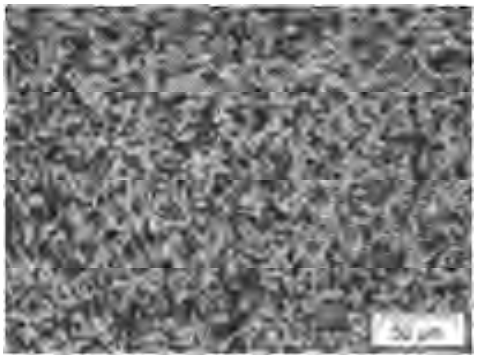

a) SEM

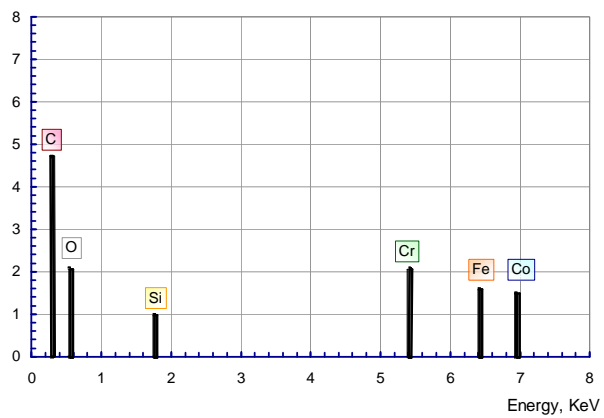

Post-test

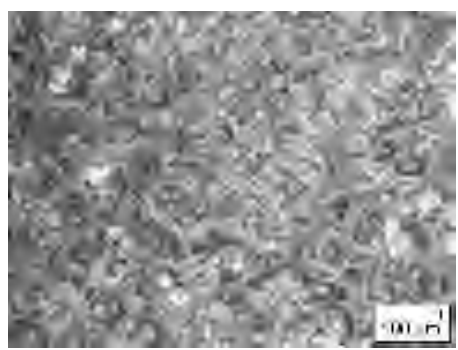

$100 \mu \mathrm{m}$

b) X-ray florescence analysis, exposure 3-minutes at $T_{W}=1617 \mathrm{~K}$

Figure 9. Effect of arc-jet exposure on surface morphology and chemistry of the CC-2 coating.

Calculated pre- and post-test total hemispherical emittance (solid lines), using the reflectance data, are compared with the values (symbols) used in the SCFC code to predict the atom recombination coefficients, Figure 10.

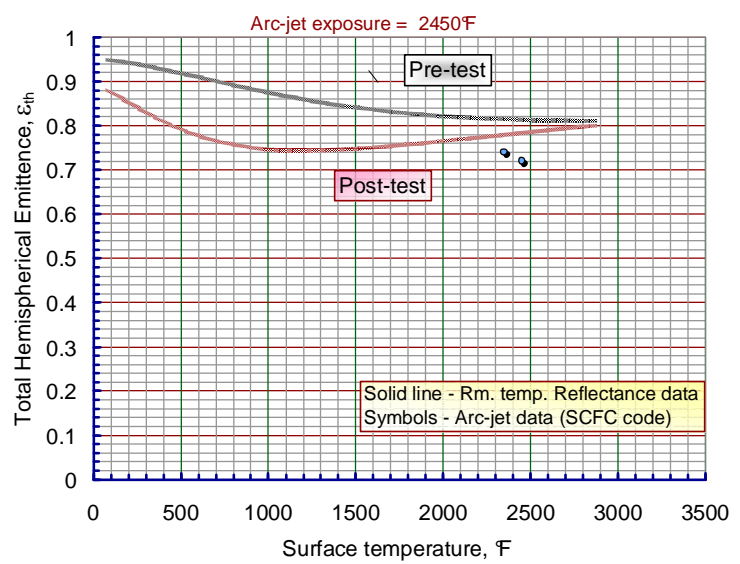

Figure 10. Effect of arc-jet exposure on the emittance of the CC-2 coating.

The total hemispherical emittance derived from the arc-jet data are lower than values obtained from the room temperature reflectance data (roughly 0.73 compared to 0.79 ). 
The atom recombination coefficients for both oxygen and nitrogen for the CC-2 coating are plotted in Figure 11. The high temperature coefficients $\left(\mathrm{T}_{\mathrm{W}}>1256 \mathrm{~K}\right)$ were obtained using arc-jet data and the SCFC code. ${ }^{7}$ This code assumes frozen chemistry and incorporates Goulard's theory as part of the nozzle program. Coefficients at $\mathrm{T}_{\mathrm{W}}<$ $1256 \mathrm{~K}$ were obtained from side-arm-reactor data using the basic diffusion equation with appropriate boundary conditions at the tube interfaces. ${ }^{10}$ Included on the plot are the corresponding Arrhenius expressions for the data from room temperature to $1700 \mathrm{~K}\left(2600^{\circ} \mathrm{F}\right)$.

Nitrogen:

$$
\begin{aligned}
\mathrm{T}_{\mathrm{W}} & <760 \mathrm{~K} \\
\gamma_{\mathrm{N}} & =0.0032
\end{aligned}
$$

$$
\mathrm{T}_{\mathrm{W}}>760 \mathrm{~K}
$$

$$
\gamma_{\mathrm{N}}=33.0 \varepsilon^{-7013 / \mathrm{T} \omega}
$$

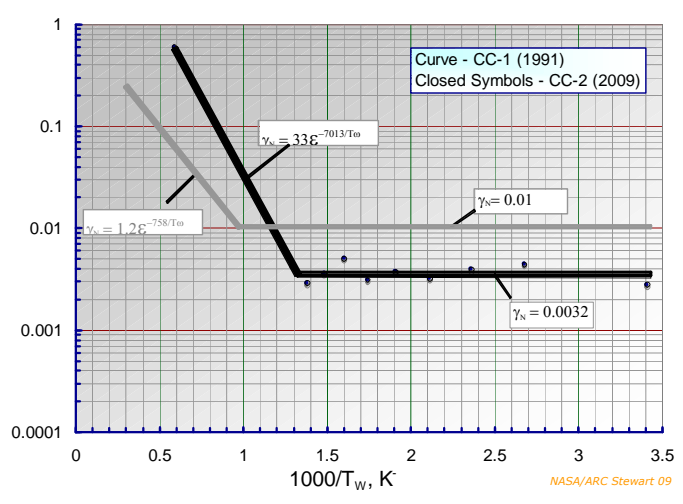

a) Nitrogen

$$
\begin{aligned}
& \text { Oxygen: } \\
& \begin{array}{c}
\mathrm{T}_{\mathrm{W}}<667 \mathrm{~K} \\
\gamma_{\mathrm{O}}=0.0045 \\
\mathrm{~T}_{\mathrm{W}}>760 \mathrm{~K} \\
\gamma_{\mathrm{O}}=12.0 \varepsilon^{-5263 / \mathrm{T} \omega}
\end{array}
\end{aligned}
$$

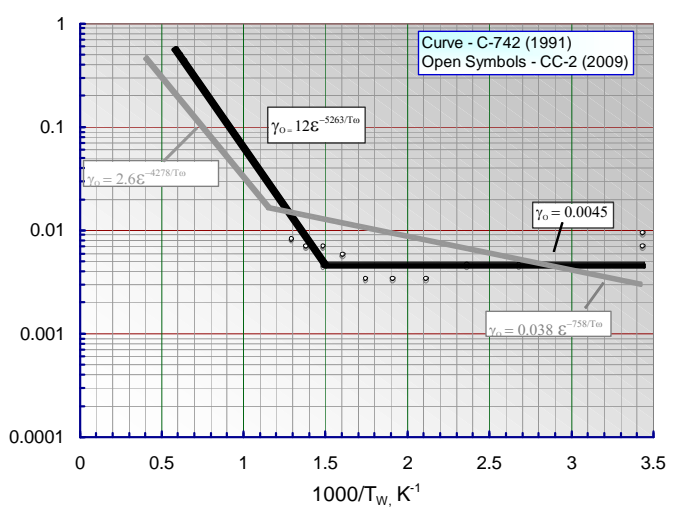

b) Oxygen

Figure 11. Atom recombination coefficients for the CC-2 coating.

The data indicates that the coefficients for both nitrogen and oxygen atom recombination for the CC-2 coating are typically lower at surface temperatures below roughly $700 \mathrm{~K}$ and increase most rapidly at higher temperatures than the original CC-1 coating used on the early shuttle flight experiments reported at the Williamsburg Symposium in $1993 .^{5}$

\section{Computational Simulations}

A full Navier-Stokes solver, DLPR code ${ }^{12}$ is used to predict the surface temperature profile over the flat-plate test article used during the Phase I study. The test article was exposed at an angle-of-attack of $30^{\circ}$ to the highenergy arc-jet flow. The DPLR solution used surface properties calculated from the data obtained in the Phase II study.

Figure 12 shows the computational grid and location of the RCG and CC-2 coatings. The predicted threedimensional surface temperature distribution and centerline temperature profile over the flat-plate are shown in Figure 13.

The calculations were made by defining the flow properties at the sonic point in the nozzle throat and then processing downstream across the bow shock wave and over the test article surface. The measured surface temperatures taken from the flat plate agreed well with the predicted centerline temperature profile calculated from DLPR. 


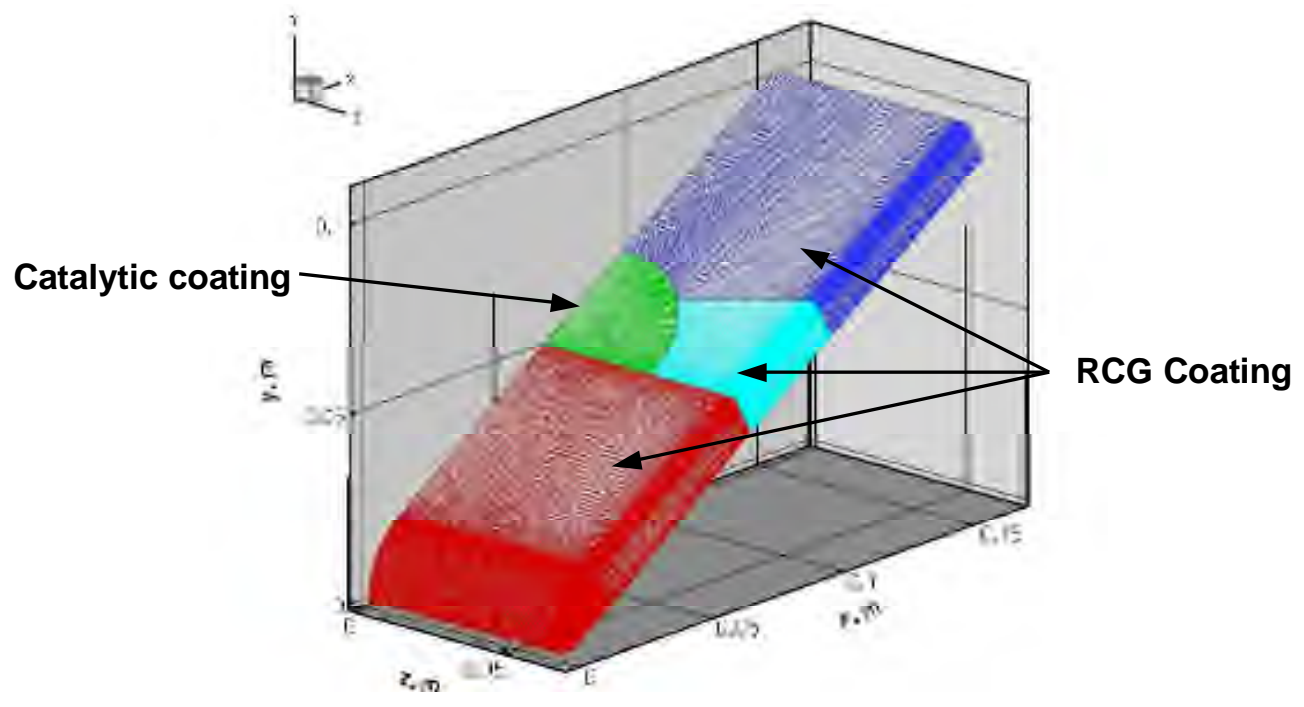

Figure 12. Computational grid used for flat-plate DLPR solution $\left(R_{N}=0.022\right.$ m).

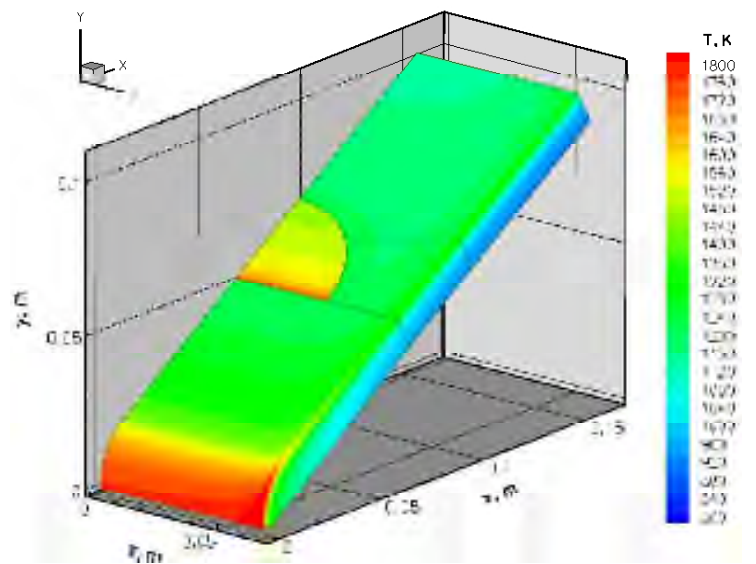

(a) Computed temperature

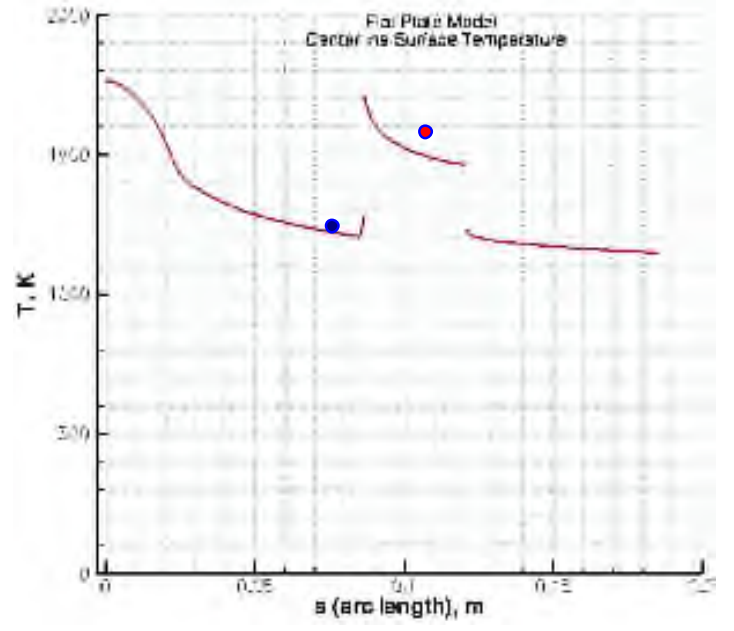

(b) Comparison of predicted and measured data Figure 13. Predicted surface temperature contours and centerline profile over the flat plate. AHF 24-inch nozzle flow: $\mathrm{H}_{\mathrm{e} 0}=12.3 \mathrm{MJ} / \mathrm{kg}, P_{\mathrm{CH}}=1.72 \mathrm{~atm}$

Finally, Figure 14 indicates that the shear load during the Phase I study on the flat plate (roughly $30 \mathrm{~Pa}$ ) was close to the value predicted for the laminar flight case, but roughly half that predicted for the turbulent flight case. 


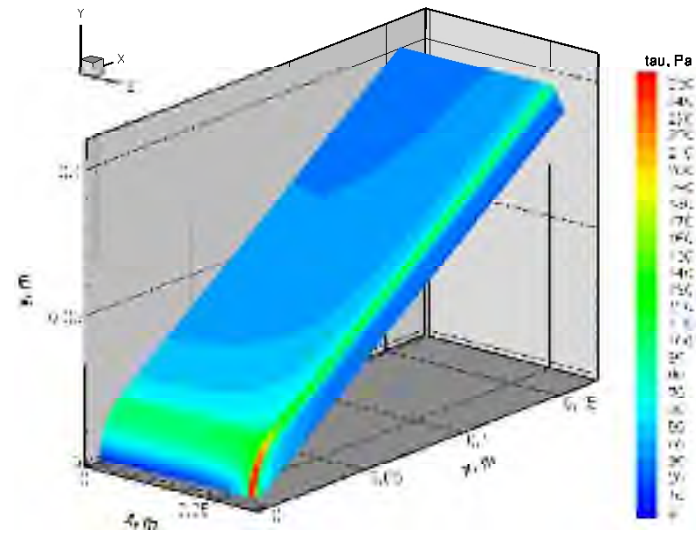

(a) Computed surface shear

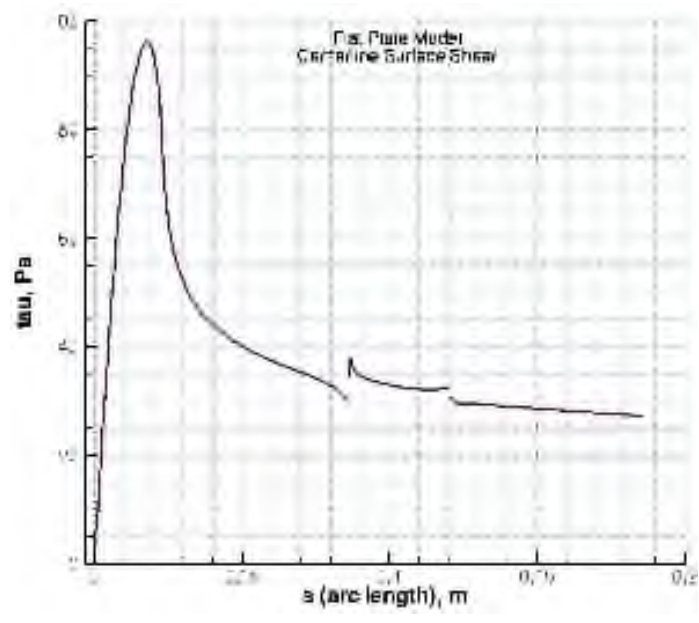

(b) Predicted shear distribution along flat-plate

Figure 14. Predicted surface shear contours and profile along model centerline.

\section{Summary}

Results from the screening and surface characterization studies conducted the NASA Ames Research Center AHF showed:

- Elemental analysis indicates that candidate coating $15 \mathrm{E}$ (reacted oxides similar to C-742) was not chemically stable after arc-jet exposure to $1589 \mathrm{~K}$ for nine minutes. It should be noted that the $\mathrm{CC}-1$ coating was never used in a flight experiment above $1422 \mathrm{~K}\left(2100^{\circ} \mathrm{F}\right)$; therefore was not required to be stable above $1478 \mathrm{~K}$ $\left(2200^{\circ} \mathrm{F}\right)$.

- Elemental analysis indicates that $15 \mathrm{~B}$ (CC-2 coating) was chemically stable during a nine-minute exposure at a surface temperature of $1589 \mathrm{~K}\left(2400^{\circ} \mathrm{F}\right)$ in the high-enthalpy hypersonic arc-jet stream. Therefore, it was chosen as the coating for the flight experiment.

- Total hemispherical emittance of the CC-2 coating at $1589 \mathrm{~K}\left(2400{ }^{\circ} \mathrm{F}\right)$ is somewhat lower than $\mathrm{RCG}\left(\varepsilon_{\mathrm{th}}=\right.$ 0.85). Emittance calculated from post-test reflectance data was 0.78 for $\mathrm{T}_{\mathrm{W}}=1589 \mathrm{~K}$.

- Atom recombination coefficients have been calculated from both arc-jet test and side-arm-reactor data. Arrhenius expressions developed for surface temperatures from room temperature to $1700 \mathrm{~K}$ showed that in general the coefficients for CC-2 are higher than the CC-1 coating above $1000 \mathrm{~K}$.

- No noticeable recession was measured on the LI-900 blunt cone after a stagnation test at $1700 \mathrm{~K}$ for an exposure of 3-minutes.

\section{Acknowledgments}

The authors would like to thank the ceramic laboratory and in particular Jeff Figone and Matt Switzer for their contributions to the development of test articles and coating application for this study. The authors would also like to acknowledge the support from NASA Ames Space Technology Division through contract NNA04BC25C to ELORET Corporation. In particular, Mike Gusman, Jose Garcia Chavez, and Jerry Ridge for their help in the development of the reacted oxides (coating 15E) and providing pre and post-test surface characterization data from the test articles.

\section{References}

${ }^{1}$ Stewart, D. A., Rakich, J. V., and Lanfranco, M. J., "Catalytic Surface Effects Experiment on Space Shuttle," AIAA Paper 81-0143, Palo Alto, CA, 1981. 
${ }^{2}$ Stewart, D. A., Rakich, J. V., and Lanfranco, M. J., "Results of a Flight Experiment on the Catalytic Efficiency of the Space Shuttle Heat Shield,” AIAA Paper 82-0944, St. Louis, MO, 1982.

${ }^{3}$ Stewart, D. A., Rakich, J. V., and Lanfranco, M. J., "Catalytic Surface Effect Space Shuttle Thermal Protection System During Earth Entry of Flights STS-2through STS-5,” Shuttle Performance: Lessons Learned, NASA CP2283, part 2, 1983.

${ }^{4}$ Stewart, D. A., "Catalytic Surface Effects Experiment for Space Shuttle," Orbiter Experiments (OEX) Aerothermodynamics Symposium, Williamsburg, VA, April, 1993, pg. 171.

${ }^{5}$ Stewart, D. A., "Flight Experiment Demonstrating the Effect of Surface Catalysis on the Heating Distribution Over the Space Shuttle Heat Shield," Orbiter Experiments (OEX) Aerothermodynamics Symposium, Williamsburg, VA, April, 1993, pg. 677-701.

${ }^{6}$ Ames Research Facilities Summary, NASA Ames Research Center, Moffett Field, CA 1974.

${ }^{7}$ Stewart, D. A., Gökçen, T., and Chen, Y. K., "Characterization of Hypersonic Flows in the AHF and IHF NASA Ames ArcJet Facilities,” AIAA Paper 09-4237, San Antonio, TX, June 2009.

${ }^{8}$ Pallix, J. B., and Copeland, R. A.<"Measurement of Catalytic Recombination Coefficients on Quartz Using Laser-Induced Fluorescence. J. Thermophysics and Heat Transfer, Vol. 10,No.2, 1996, pp. 224-233.

${ }^{9}$ Marschall, J., "Experimental Determination of Oxygen and Nitrogen Recombination Coefficients at Elevated Temperatures Using Laser-Induced Fluorescence”, National Heat Transfer Conference, Baltimore, Md., AIAA Paper 97-3879, August 1997.

${ }^{10}$ Stewart, D. A., "Surface Catalytic and Characterization of Proposed Candidate TPS for Access-to-Space Vehicles," NASA TM 112206, July 1997.

${ }^{11}$ Lees, L., "Laminar Heat Transfer Over Blunt-Nose Bodies at Hypersonic Flight Speeds," Jet Propulsion, Vol. 26, No. 4, April 1956.

${ }^{12}$ Wright, M. J., Candler, G. V., and Bose, D., "Data-Parallel Line Relaxation Method for the Navier-Stokes Equations," AIAA Journal, Vol. 36, No. 9, 1998, pp. 1603-1609. 


\title{
Development of a Catalytic Coating for a Shuttle Flight Experiment
}

\author{
David A. Stewart, ${ }^{*}$ Tahir Gökçen, ${ }^{\dagger}$ Steven E. Sepka, ${ }^{\ddagger}$ Daniel B. Leiser, ${ }^{\S}$ and Marc D. Rezin ${ }^{* *}$ \\ NASA Ames Research Center, Moffett Field, CA 94035
}

\begin{abstract}
A spray-on coating was developed for use on the Space Shuttle wing tiles to obtain data that could be correlated with computational fluid dynamics (CFD) solutions to better understand the effect of chemical heating on a fore-body heat shield having a turbulent boundary layer during planetary entry at hypersonic speed. The selection of a spray-on coating was conducted in two phases: Phase I, screening tests to select the catalytic coating formulation; and Phase II, surface property determination using both arc-jet and side-arm facilities at NASA Ames Research Center. Comparison of the predicted surface temperature profile over a flat-plate with measured values obtained during arc-jet exposure (Phase I study) was used to validate the surface properties obtained during Phase II.
\end{abstract}

\section{Nomenclature}

$\mathrm{H}_{\mathrm{o}} \quad=$ total enthalpy, $\mathrm{MJ} / \mathrm{kg}$

$\mathrm{H}_{\mathrm{eo}} \quad=$ total enthalpy at the boundary layer edge, $\mathrm{MJ} / \mathrm{kg}$

$\mathrm{I}_{\mathrm{x}} \quad=$ intensity of element $\mathrm{x}$ in $\mathrm{x}$-ray florescence analysis, arbitrary scale

$\mathrm{M} \quad=$ Mach number

$\mathrm{M}_{\mathrm{f}} \quad$ = Mach number at which the nozzle flow is assumed to be chemically frozen (in the SCFC code)

$\mathrm{M}_{\infty} \quad=$ free stream Mach number for the arc-jet models

$\mathrm{P}_{\mathrm{o}} \quad=$ model stagnation pressure or pitot pressure, atm

$\mathrm{P}_{\mathrm{CH}} \quad=$ arc-heater chamber pressure, atm

$\mathrm{p} \quad=$ pressure, $\mathrm{Pa}$

$\mathrm{R}_{\mathrm{N}} \quad=$ model nose radius, $\mathrm{m}$

$\mathrm{s} \quad=$ arc length, $\mathrm{m}$

$\mathrm{T}=$ temperature, $\mathrm{K}$

$\mathrm{T}_{\mathrm{w}} \quad=$ wall temperature, $\mathrm{K}$

$\mathrm{T}_{\mathrm{w} \text { RCG }}=$ wall temperature of the reaction-cured glass article, $\mathrm{K}$

tau $=$ shear, $\mathrm{Pa}$

$\mathrm{U} \quad=$ velocity, $\mathrm{m} / \mathrm{s}$

$\mathrm{U}_{\infty} \quad=$ free stream velocity, $\mathrm{m} / \mathrm{s}$

$\varepsilon_{\text {th }}=$ total hemispherical emittance

$\gamma_{\mathrm{N}} \quad=$ nitrogen atom recombination coefficient

$\gamma_{\mathrm{O}} \quad=$ oxygen atom recombination coefficient

$\gamma_{\infty} \quad=$ ratio of specific heats for the free stream gas (in the SCFC code)

\section{Introduction}

$\mathrm{T}$

HE effect of surface catalysis on heating to a vehicle entering the Earth atmosphere at hypersonic speed was first demonstrated during the catalytic surface effects Orbiter flight experiments conducted in the early 1980s. ${ }^{1-5}$ These experiments, used a cobalt iron chromium oxide spinel, designated as C-742, mixed with a Polyvinyl acetate

\footnotetext{
* Senior Research Scientist, Thermal Protection Materials and Systems Branch, MS 234-1

${ }^{\dagger}$ Senior Research Scientist, ELORET Corporation, MS 230-2, Senior Member AIAA

* Senior Research Scientist, ELORET Corporation

${ }^{\S}$ Senior Research Scientist, Thermal Protection Materials and Systems Branch

${ }^{* *}$ Aerospace Engineer, Thermal Protection Materials and Systems Branch
}

1

American Institute of Aeronautics and Astronautics 
(PVA) binder. It was sprayed on selected tiles over the lower surface of the fuselage and wing of the Orbiter. Surface temperature measurements were taken during the portion of the trajectory where the boundary layer was laminar $\left(\mathrm{M}_{\infty}>10\right)$. This coating was referred to as CC-1. The present boundary layer transition (BLT) experiment will investigate the effect of a high catalytic efficiency surface on heating during Earth entry with a turbulent boundary layer at Mach numbers near 18 using a similar spray-on coating to the CC- $1{ }^{6}$ Since the C-742 spinel is no longer available, candidate formulations with similar spinel structure and surface properties to the $\mathrm{CC}-1$ coating were developed for the BLT flight experiment.

The two coatings evaluated as a replacement for the CC-1 coating included a mixture of two spinels (15B) and a formulation of reacted oxides (15E). Coating 15B was formulated by directly mixing a small amount of glass frit with cobalt-chromium and cobalt-iron spinels. Coating $15 \mathrm{E}$ was formulated by first reacting the appropriate amount of chromium, iron, and cobalt oxides to create a single spinel having a similar structure to the C-742; then a small amount of silicon dioxide (Quartz frit) was mixed with the spinel powder. Polyvinyl acetate (PVA) was used as the binder for both coatings.

\section{Test Facilities}

\section{A. Arc-Jet Facility}

The arc-jet tests were conducted in the Aerodynamic Heating Facility (AHF). ${ }^{7}$ A sketch of the AHF is shown in Figure 1a. The facility uses a constricted arc-heater to provide high-energy dissociated hypersonic flow over a test model positioned downstream of the 8 degree half-angle conical nozzle. A large boiler plant is used to maintain the pressure ratio between the arc-heater and test-section required for steady-state hypersonic flow.

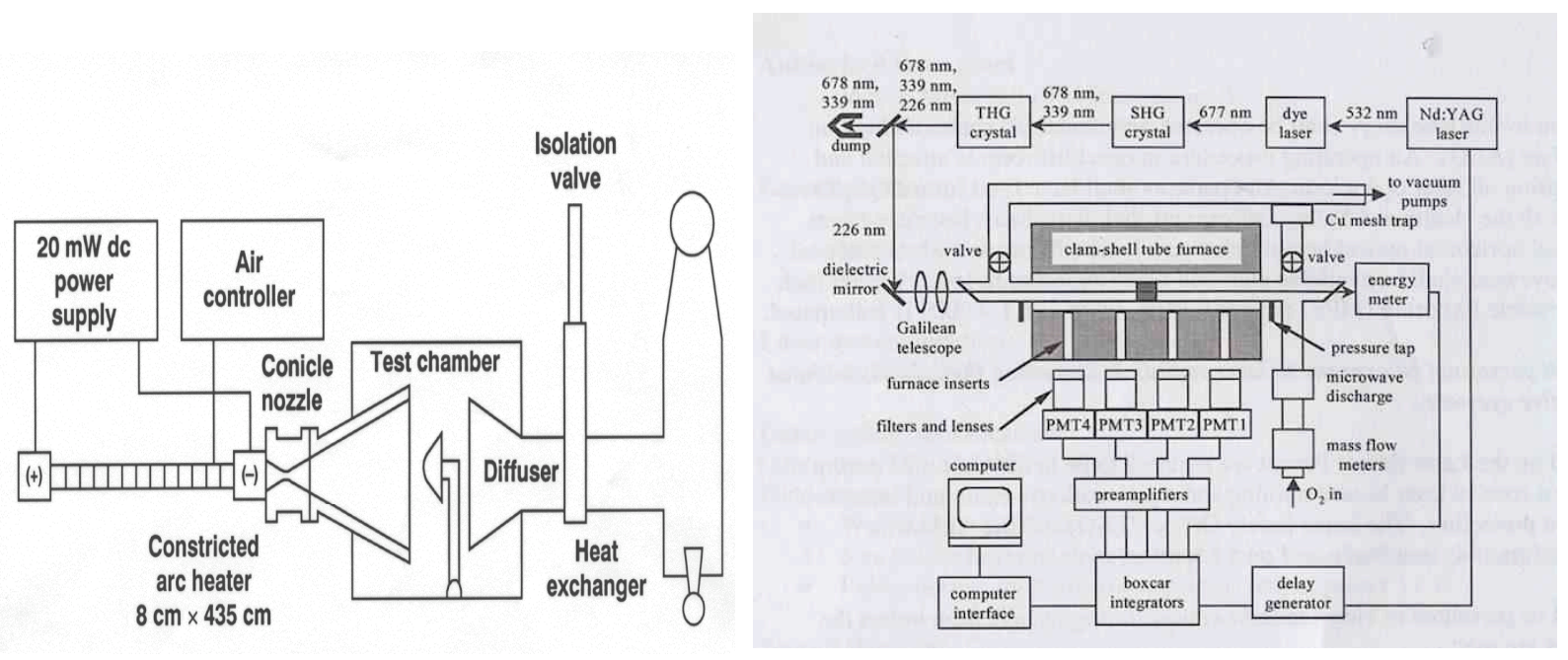

(a) Aerodynamic Heating Facility

(b) Side-Arm Reactor

Figure 1. Schematics of test facilities.

Either nitrogen or air can be easily used as the test gas without altering the heater hardware. This permits measurements of heat flux and temperature to be taken in consecutive order from a test model. Surface conditions on the test model are varied by changing the 1) exit diameter of the nozzle, 2) reservoir pressure, and/or 3) electrical power dissipated in the heater.

The geometric area ratio (nozzle exit to throat) of the facility can be varied from 22 to 575 . Heater pressure can be varied from $0.68 \mathrm{~atm}$ to roughly $9 \mathrm{~atm}$ and the maximum power dissipated in the heater can be increased up to 20 MW. Stagnation point enthalpy was determined using a facility system energy balance approach. ${ }^{8}$ It requires that the predicted enthalpy is compatible with all measured flow properties during each arc-jet test.

A pyrometer, radiometer, and copper hemisphere were used to measure surface temperature, heat flux and pressure during each test. 


\section{B. Side-Arm Reactor}

Figure $1 \mathrm{~b}$ shows a schematic of the side-arm-reactor used to obtain the atom recombination coefficients for both nitrogen and oxygen. The data were obtained using a three-section diffusion tube (short sample of test material, L/D $<1$, positioned between two sections of quartz tube) that was placed at the center of the clamshell tube furnace. This furnace enables the coefficients to be calculated from room temperature to $1200 \mathrm{~K}$. The test gas is dissociated using a microwave discharge upstream of the side-arm diffusion tube and the coefficients are calculated using measurements from laser-induced fluorescence (LIF) diagnostic techniques to obtain the species concentration profile along the tube centerline. ${ }^{9-10}$ The profile is obtained from the atom fluorescence measured through quartz lined optical access ports using four photomultiplier tubes (PMT) equally spaced along the furnace.

\section{Test Articles}

Test articles used during this study are shown in Figure 2. During Phase I, a disc-shaped test article coated with the reaction-cured-glass (RCG) over the front surface and approximately 1-inch down its sides, was installed into a flat-plate test fixture, Figure $2 \mathrm{a}$. The fixture was made from a high-density fibrous insulation that was also coated with RCG glass. It had a nose radius of $2.2 \mathrm{~cm}(0.875 \mathrm{in})$, length of $16.5 \mathrm{~cm}(6.5 \mathrm{in})$, and width of $12.7 \mathrm{~cm}(5.0 \mathrm{in})$. Included in the figure is a sketch of the disk that was installed in the flat plate. It had two type-R thermocouples installed symmetric to the center of the disk. The catalytic coatings were applied to the downstream half of the top surface of the disk. During Phase II, the test articles used were a blunt $5^{\circ}$ cone and a flat-faced cylinder, Figure $2 \mathrm{~b}$. During these tests, the catalytic coatings were applied over the front surface of the test article. Both Phase I and Phase II tests were conducted in the AHF using the 24-inch nozzle.

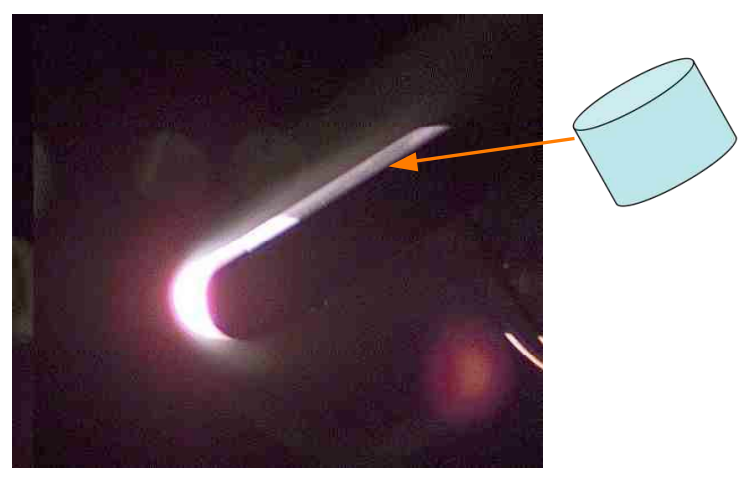

(a) Flat-plate

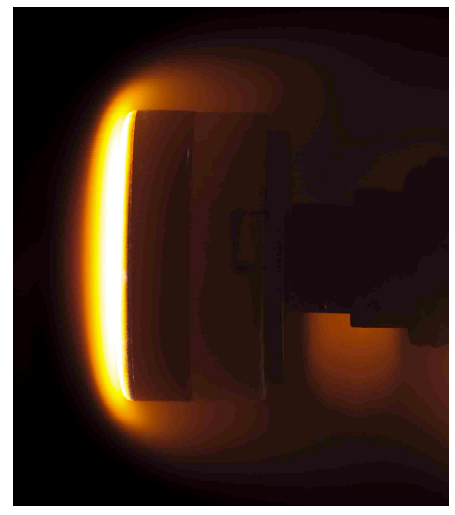

(b) Flat-face cylinder

Figure 2. Arc-jet test articles used during Phase I and Phase II studies.

\section{Experiments}

The development of a spray-on coating for the boundary-layer transition experiment was made in two phases. In Phase I, screening tests were conducted in an arc-jet stream to select one of two candidate coatings (15B and 15E). These tests were run using a flat plate at an angle-of-attack of $30^{\circ}$, shown in Figure $2 \mathrm{a}$. One of the test articles used to obtain the surface properties of the coating was the flat-faced cylinder shown in Figure $2 \mathrm{~b}$. Selection of the coating was based on the material stability during a nine-minute arc jet exposure at a surface temperature of $1589 \mathrm{~K}$ $\left(2400^{\circ} \mathrm{F}\right)$. Data used in the selection were spectral reflectance, and surface chemistry measurements that were taken before and after arc jet exposure. Also, photographs and scanning electron microphotographs (SEMs) of the samples were obtained before and after arc-jet exposure. Room temperature spectral reflectance measurements were made using a BIO-RAD model FTS 40 (wavelength range 0.25 microns to 2.5 microns) and Perkin Elmer model 310 (wavelength range 2.5 microns to 18 microns) spectrophotometers. Pre- and post-test surface chemistry was determined using x-ray fluorescence elemental analyses. Once the coating was selected as a result of Phase I study; in Phase II, both oxygen and nitrogen atom recombination coefficients for the selected coating were determined using arc jet and side-arm-reactor experiments. 
Table 1. Summary of Phase I test results.

Coating Performance

\begin{tabular}{|c|c|c|c|c|c|c|c|}
\hline Run No. & Sample & Coating & $\begin{array}{c}\mathrm{P}_{\mathrm{O}} \\
\text { atm }\end{array}$ & $\begin{array}{c}\mathrm{H}_{\mathrm{eo}} \\
\mathrm{MJ} / \mathrm{kg}\end{array}$ & $\begin{array}{c}\mathrm{T}_{W R C G} \\
\text { Meas. } \\
\mathrm{K}\end{array}$ & $\begin{array}{c}\mathrm{T}_{\text {WRCG }} \\
\text { Calc. } \\
\mathrm{K}\end{array}$ & $\begin{array}{c}\mathrm{T}_{W \text { Cat }} \\
\text { Meas. } \\
\mathrm{K}\end{array}$ \\
\hline 1 & 3608 & $15 \mathrm{E}$ & 0.012 & 13.5 & 1244 & 1228 & 1594 \\
\hline 2 & 3610 & $15 \mathrm{~B}$ & 0.013 & 13.5 & 1250 & 1228 & 1589 \\
\hline
\end{tabular}

Calculated from SCFC code assuming $\varepsilon_{t h}=0.85$ and using RCG atom recombination coefficients for oxygen and nitrogen.

Free-stream Properties

AHF 24-inch nozzle exit

\begin{tabular}{|c|c|c|c|c|c|}
\hline $\begin{array}{c}\mathrm{P}_{\mathrm{CH}} \\
\mathrm{atm}\end{array}$ & $\mathrm{M}_{\mathrm{f}}$ & $\mathrm{M}_{\infty}$ & $\begin{array}{c}\mathrm{T}_{\infty} \\
\mathrm{K}\end{array}$ & $\gamma_{\infty}$ & $\begin{array}{c}\mathrm{U}_{\infty} \\
\mathrm{m} / \mathrm{s}\end{array}$ \\
\hline 1.7 & 1.8 & 8.03 & 608 & 1.37 & 4145 \\
\hline
\end{tabular}

Free-stream Flow Chemistry

(mole fraction)

\begin{tabular}{|c|c|c|c|c|c|}
\hline $\mathrm{N}$ & $\mathrm{N}_{2}$ & $\mathrm{O}$ & $\mathrm{O}_{2}$ & $\mathrm{NO}$ & $\mathrm{Ar}$ \\
\hline 0.122 & 0.41 & 0.247 & --- & 0.004 & 0.22 \\
\hline
\end{tabular}

Table 2. Summary of Phase II test results: surface characterization of the CC-2 coating.

\begin{tabular}{|c|c|c|c|c|c|c|c|}
\hline \multicolumn{8}{|c|}{ Coating Performance } \\
\hline Run No. & Sample & Gas & $\begin{array}{l}\mathrm{P}_{\mathrm{CH}} \\
\text { atm }\end{array}$ & $\begin{array}{l}\mathrm{P}_{\mathrm{O}} \\
\mathrm{atm}\end{array}$ & $\begin{array}{c}\mathrm{H}_{\mathrm{eo}} \\
\mathrm{MJ} / \mathrm{kg}\end{array}$ & $\begin{array}{c}\mathrm{T}_{\mathrm{W}} \\
\text { Meas. } \\
\mathrm{K}\end{array}$ & $\begin{array}{c}\mathrm{T}_{\mathrm{W}} \\
\text { Calc. } \\
\mathrm{K}\end{array}$ \\
\hline 2,5 & RCG & Air & 0.78 & 0.006 & 13.0 & 1361 & 1356 \\
\hline 2 & $\mathrm{FF}(4-1)$ & \multicolumn{4}{|c|}{$\varepsilon_{\mathrm{th}}=0.74$, Coefficients: $\gamma_{\mathrm{N}}=0.5, \gamma_{\mathrm{O}}=0.44$} & 1564 & 1561 \\
\hline 5 & BC 3614 & \multicolumn{4}{|c|}{$\varepsilon_{\text {th }}=0.72$, Coefficients: $\gamma_{N}=0.5, \gamma_{0}=0.44$} & 1617 & 1622 \\
\hline 3,4 & RCG & Nitrogen & 0.78 & 0.006 & 15.1 & 1378 & 1394 \\
\hline 3 & $\mathrm{FF}(4-3)$ & \multicolumn{4}{|c|}{ Coefficient: $\gamma_{N}=0.5$} & 1611 & 1617 \\
\hline 4 & BC 3615 & \multicolumn{4}{|c|}{ Coefficient: $\gamma_{N}=0.59$} & 1689 & 1700 \\
\hline 5 & BC LI-1500 & & & & & 1700 & 1689 \\
\hline
\end{tabular}

Free-stream Flow Chemistry

(mole fraction)

\begin{tabular}{|c|c|c|c|c|c|c|}
\hline Run No. & $\mathrm{N}$ & $\mathrm{N}_{2}$ & $\mathrm{O}$ & $\mathrm{O}_{2}$ & $\mathrm{NO}$ & $\mathrm{Ar}$ \\
\hline $2-5$ & 0.16 & 0.40 & 0.25 & ---- & 0.004 & 0.19 \\
\hline $3-4$ & 0.37 & 0.44 & $\mathrm{~N} / \mathrm{A}$ & $\mathrm{N} / \mathrm{A}$ & $\mathrm{N} / \mathrm{A}$ & 0.19 \\
\hline 5 & 0.21 & 0.36 & 0.24 & --- & 0.003 & 0.18 \\
\hline
\end{tabular}




\section{Results and Discussion}

The arc-jet test data taken during Phases I and II are summarized in Tables 1 and 2, respectively.

The screening arc-jet tests (Table 1) were conducted at a total enthalpy of $13.5 \mathrm{MJ} / \mathrm{kg}(5800 \mathrm{Btu} / \mathrm{lbm})$ and impact pressure of $0.012 \mathrm{~atm}$. The dissociated species in the shock layer predicted by the SCFC code are given in Table 1, in terms of mole fractions: the oxygen was fully dissociated (0.247), and the nitrogen was partially dissociated (0.122). In addition, roughly 0.22 -mole fraction of argon was present. The measured surface temperature on the RCG-coated portion of the flat-plate test article was $1244 \mathrm{~K}\left(1780^{\circ} \mathrm{F}\right)$, and the measured temperature on the downstream portion of the disk with the catalytic coating was $1589 \mathrm{~K}\left(2400{ }^{\circ} \mathrm{F}\right)$. The calculated value in Table 1 was predicted using RCG atom recombination coefficients, the SCFC code, and assuming a Lee's heating distribution from the stagnation point to the location where the measurement was taken on the disk. ${ }^{10,11}$

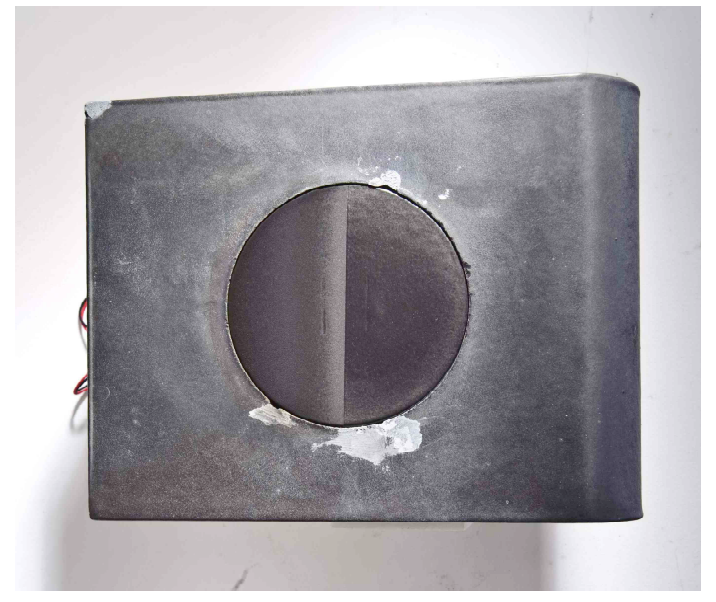

15B (spinel mixtures)

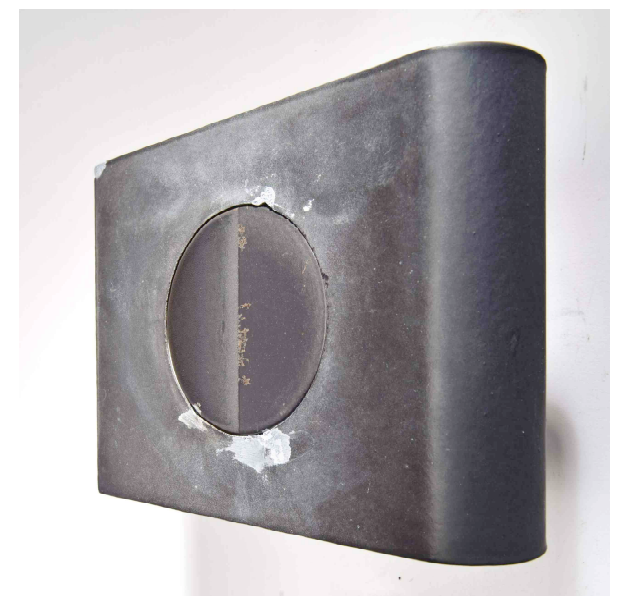

15E (reacted oxides)

a) Photographs of the test articles after a nine-minute exposure, $T_{W}=1589 \mathrm{~K}$
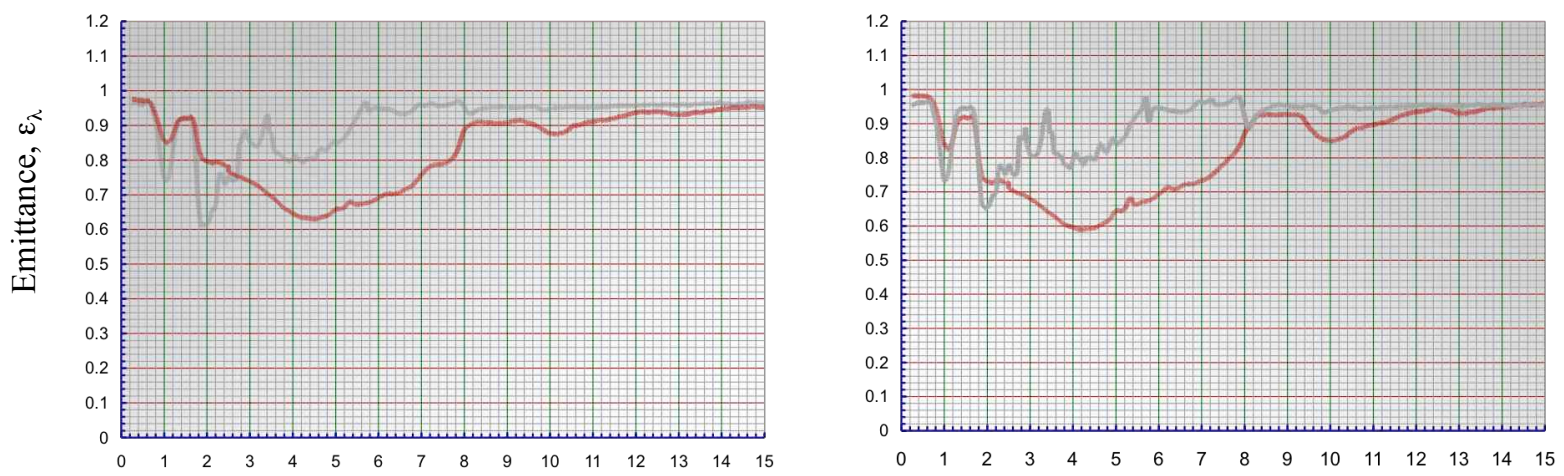

Wavelength, $\lambda$, microns

\section{b) Spectral hemispherical emittance}

Figure 3. Effect of arc-jet exposure on surface properties of the candidate coatings.

The Phase II tests were conducted using both nitrogen and air gas at a free-stream Mach number over 8 . The predicted mole fraction of the dissociated nitrogen was 0.37 in the nitrogen environment, and it was 0.16 to 0.21 in the air environments with the oxygen fully dissociated (0.25). During these tests, the total enthalpy was estimated to be $15.1 \mathrm{MJ} / \mathrm{kg}(6500 \mathrm{Btu} / \mathrm{lbm})$ for the nitrogen test gas and in the range from $13.0 \mathrm{MJ} / \mathrm{kg}(5600 \mathrm{Btu} / \mathrm{lbm})$ to 14.5 $\mathrm{MJ} / \mathrm{kg}(6250 \mathrm{Btu} / \mathrm{lbm})$ for air. The stagnation point pressure was roughly $0.006 \mathrm{~atm}$ during both tests, and the surface temperature on the test articles ranged from $1361 \mathrm{~K}\left(1990^{\circ} \mathrm{F}\right)$ to $1700 \mathrm{~K}\left(2600^{\circ} \mathrm{F}\right)$. The LI-900 test article with the CC-2 coating was exposed to the hypersonic stream for 3 minutes at $1700 \mathrm{~K}\left(2600{ }^{\circ} \mathrm{F}\right)$ and showed no 
recession after exposure. Table 2 lists the calculated atom recombination coefficients for both nitrogen and oxygen obtained using the test data and the SCFC code. The coefficients for oxygen were 0.44 at $1561 \mathrm{~K}\left(\mathrm{~T}_{\mathrm{W}}=2350{ }^{\circ} \mathrm{F}\right)$ and 0.5 at $1617 \mathrm{~K}\left(\mathrm{~T}_{\mathrm{W}}=2450^{\circ} \mathrm{F}\right)$. Coefficients for nitrogen were 0.5 at $1617 \mathrm{~K}\left(\mathrm{~T}_{\mathrm{W}}=2450{ }^{\circ} \mathrm{F}\right)$ and 0.59 at $1689 \mathrm{~K}$ $\left(\mathrm{T}_{\mathrm{W}}=2580^{\circ} \mathrm{F}\right)$. Within this temperature range, the average total hemispherical emittance ranged from 0.72 to 0.74 based on the arc-jet data.

\section{A. Phase I: Screening Arc-Jet Tests}

Figure $3 \mathrm{a}$ shows the photographs of the test articles after arc-jet exposure. The surface color of both $15 \mathrm{E}$ and 15B coatings are similar to the RCG coating. Comparison of pre and post-test emittance for both coatings are shown in Figure $3 b$. The emittance plotted was obtained from spectral hemispherical reflectance data applying Ohm's law, which assumes that the coating is opaque. The emittance decreased between roughly 2.5 and 8 microns after arc-jet exposure. The decrease in emittance is attributed to the loss of the PVA during the initial portion of the exposure.

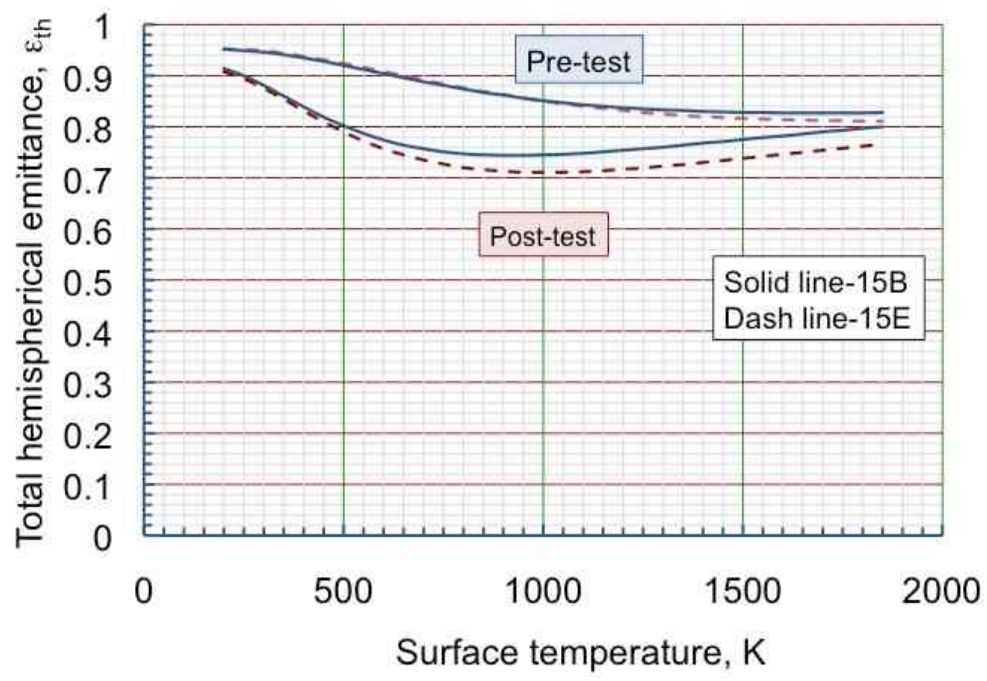

Figure 4. Effect of arc-jet exposure on emittance after nine minutes at $\mathrm{T}_{\mathrm{W}}=1589 \mathrm{~K}\left(2400{ }^{\circ} \mathrm{F}\right)$.

Figure 4 shows the effect of arc-jet exposure on total hemispherical emittance as a function of temperature for both coatings. The total hemispherical emittance was calculated from the spectral emittance values by integrating between appropriate wavelengths. Pre-test values show close similarity between the two coatings. However, posttest values show that $15 \mathrm{E}$ is slightly lower than $15 \mathrm{~B}$ after arc-jet exposure.

In Figures 5 and 6, pre- and post-test morphology and surface chemistry of the two coatings were compared using SEM and elemental analysis (x-ray fluorescence analysis). These data indicated that the coating remained on the surface after arc-jet exposure. Note change in magnification between pre- and post-test data. The elemental analysis is plotted using an intensity normalized by the value for silica since silica is stable at this surface temperature. The data taken both from $15 \mathrm{E}$ and $15 \mathrm{~B}$ coatings show the expected loss of carbon due to removal of PVA binder. In addition, the data indicate the loss of all three oxides from 15E coating. The data taken from 15B coating show little change in the relative intensity of the elements, which suggests that it remained chemically stable during the exposure to the dissociated arc-jet flow.

From the screening tests 15B (spinel mixtures) was chosen as the coating for the flight experiment because it was more chemically stable during exposure to the high-energy hypersonic arc jet flow. This coating was renamed CC-2 and is referred as such throughout the Phase II study and subsequent documentation (specifications, and so forth). 

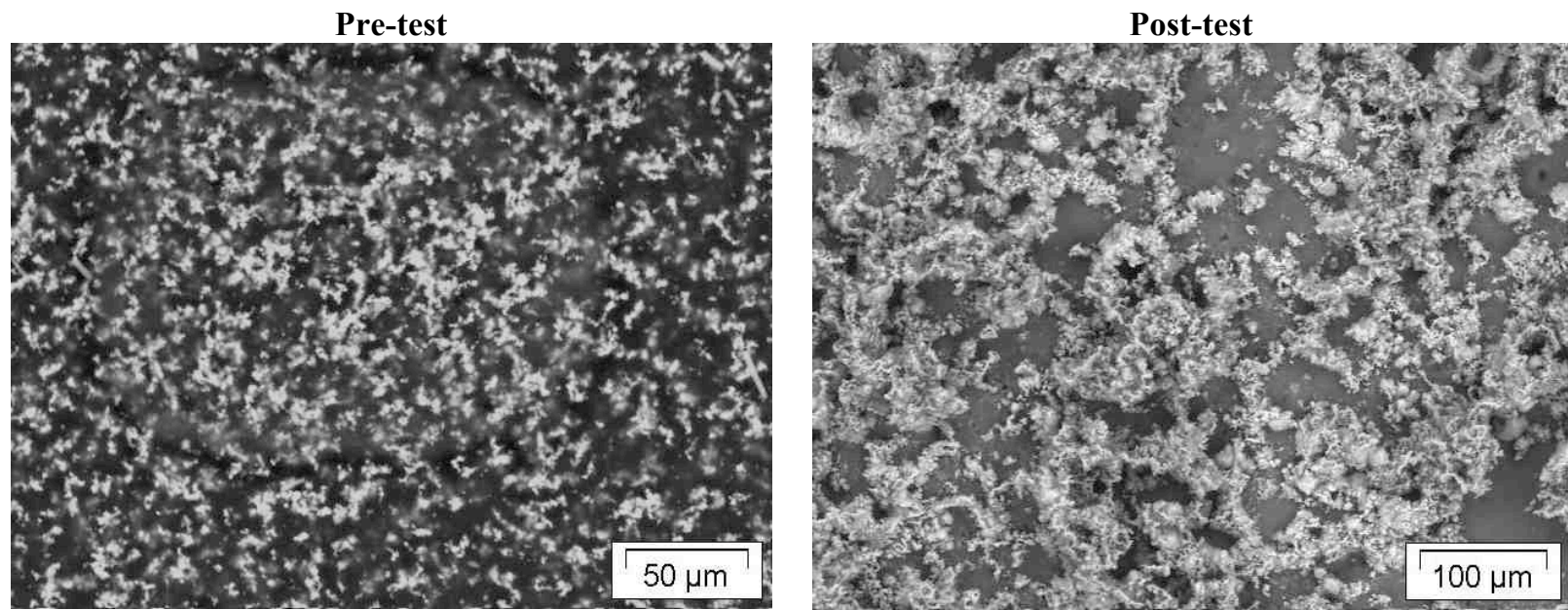

a) SEM
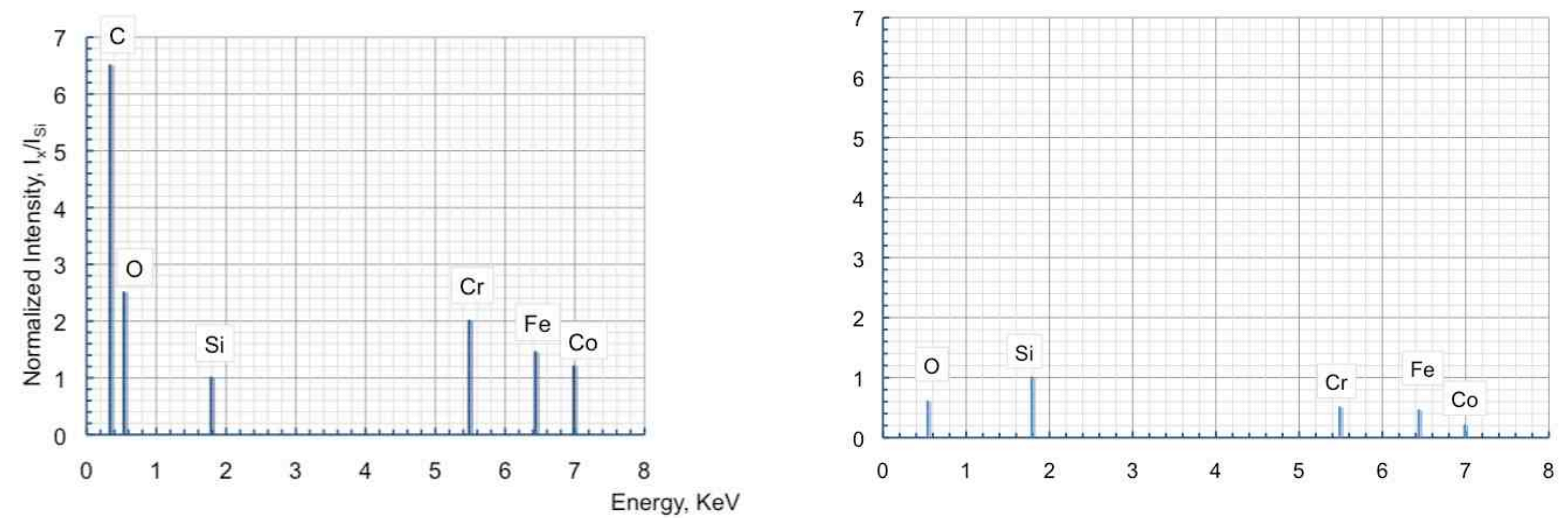

(b) Elemental analysis

Figure 5. SEM and $x$-ray florescence analysis of the $15 E$ coating. 

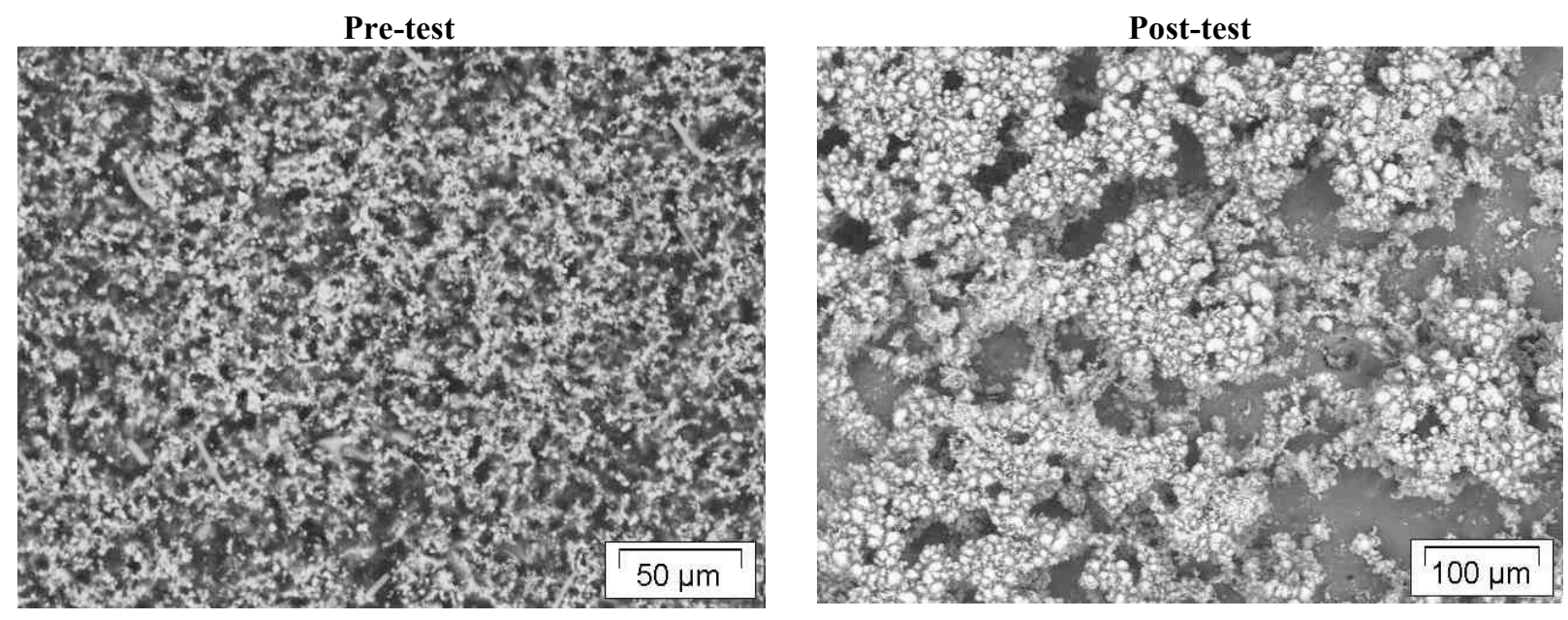

a) SEM
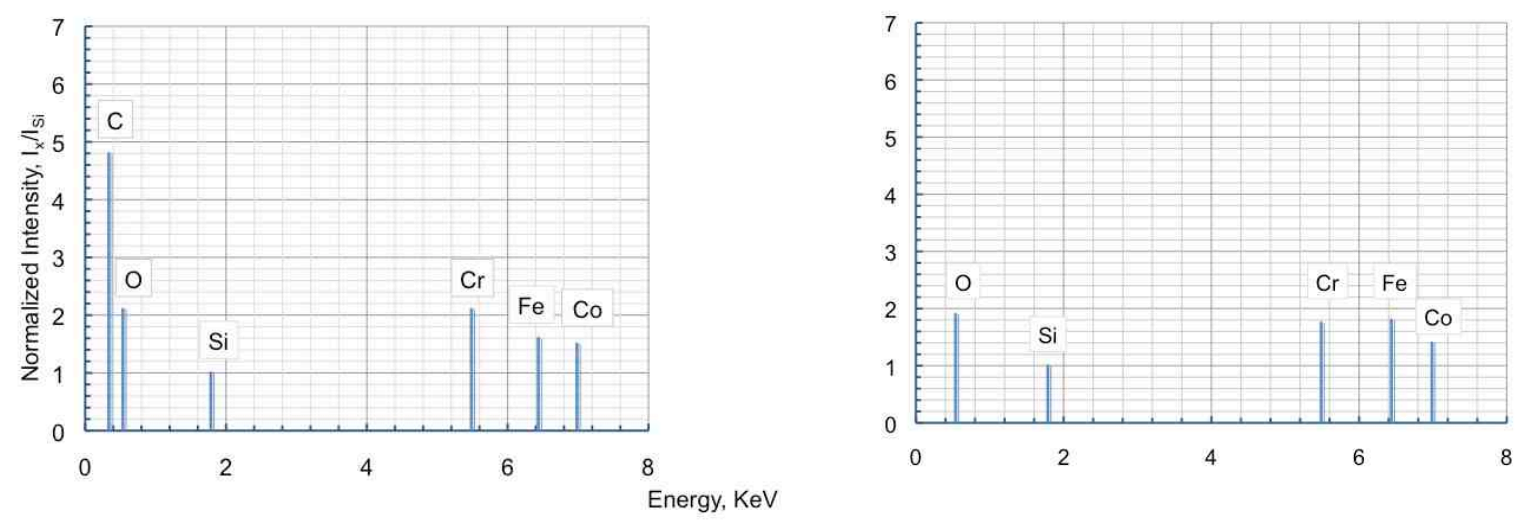

(b) Elemental analysis

Figure 6. SEM and $x$-ray florescence analysis of the $15 B$ coating. 


\section{B. Phase II: Characterization of CC-2 Coating Surface Properties}

Figures 7 shows pre- and post-test photographs of the test article used in the Phase II study. Included in Figure 7 is a photograph of the RCG reference model. The post-test photographs of the CC-2 coating were taken after a 3minute exposure at a surface temperature of $1617 \mathrm{~K}\left(2450^{\circ} \mathrm{F}\right)$ to the hypersonic air test environment. These posttest photographs show that CC-2 coating appears to be closer in color to the RCG reference model.

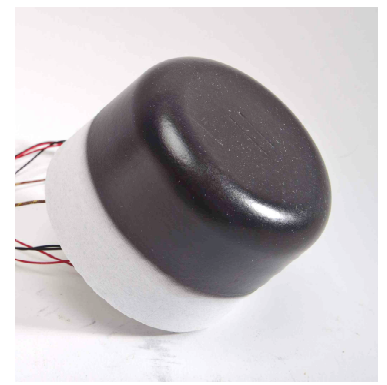

a) RCG reference

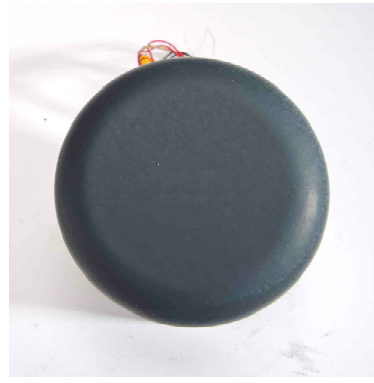

b) Pre-test

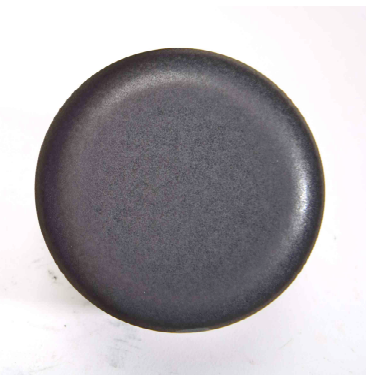

c) Post-test, $T_{W}=1617 \mathrm{~K}$

Figure 7. Effect of arc-jet exposure on CC-2 coated blunt $5^{\circ}$ cone.

The color change is attributed to the loss of PVA from the surface of the test article.

Figure 8 compares the surface temperature time histories of the CC-2 and RCG coated test articles obtained during Run 2 (air) and Run 4 (nitrogen). These data show that the surface temperature of the CC-2 coating reaches a steady-state condition during the test in air, but it does not quite reach a steady-state condition during the exposure in nitrogen. Also, the surface temperature difference between the RCG and CC-2 coated samples is slightly higher in nitrogen $\left(500^{\circ} \mathrm{F}\right)$ than in $\operatorname{air}\left(400^{\circ} \mathrm{F}\right)$.

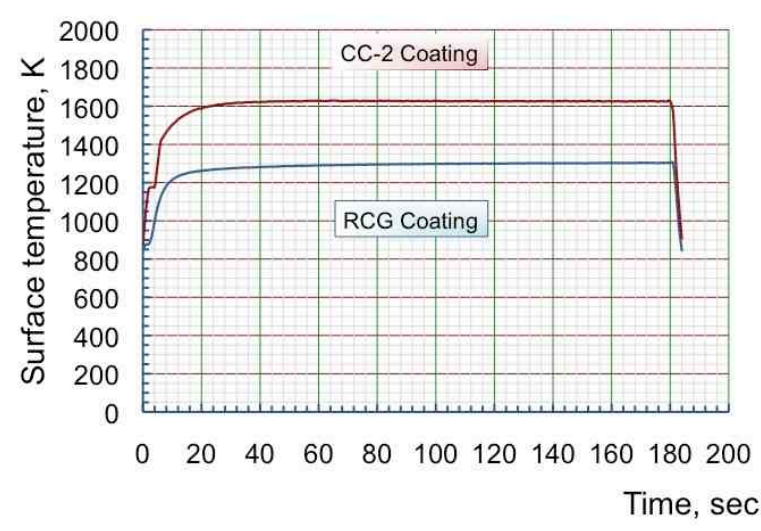

(a) Air

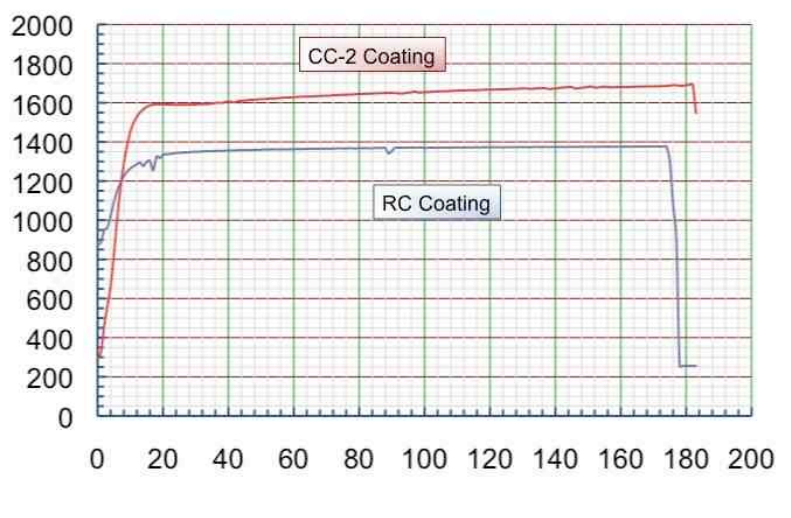

(b) Nitrogen

Figure 8. Temperature-time history of RCG and CC-2 coated surface during arc-jet exposure.

In Figures 9, pre- and post-test morphology and surface chemistry of the CC-2 coating were compared using SEM and $x$-ray elemental analysis. Pre and post-test SEMs and x-ray analysis suggest that after exposure at $1617 \mathrm{~K}$ $\left(2450^{\circ} \mathrm{F}\right)$ in the air test environment, the coating remained intact but became slightly oxidized.

Figure 10 shows the effect of arc-jet exposure on total hemispherical emittance as a function of temperature for the $\mathrm{CC}-2$ coating. 

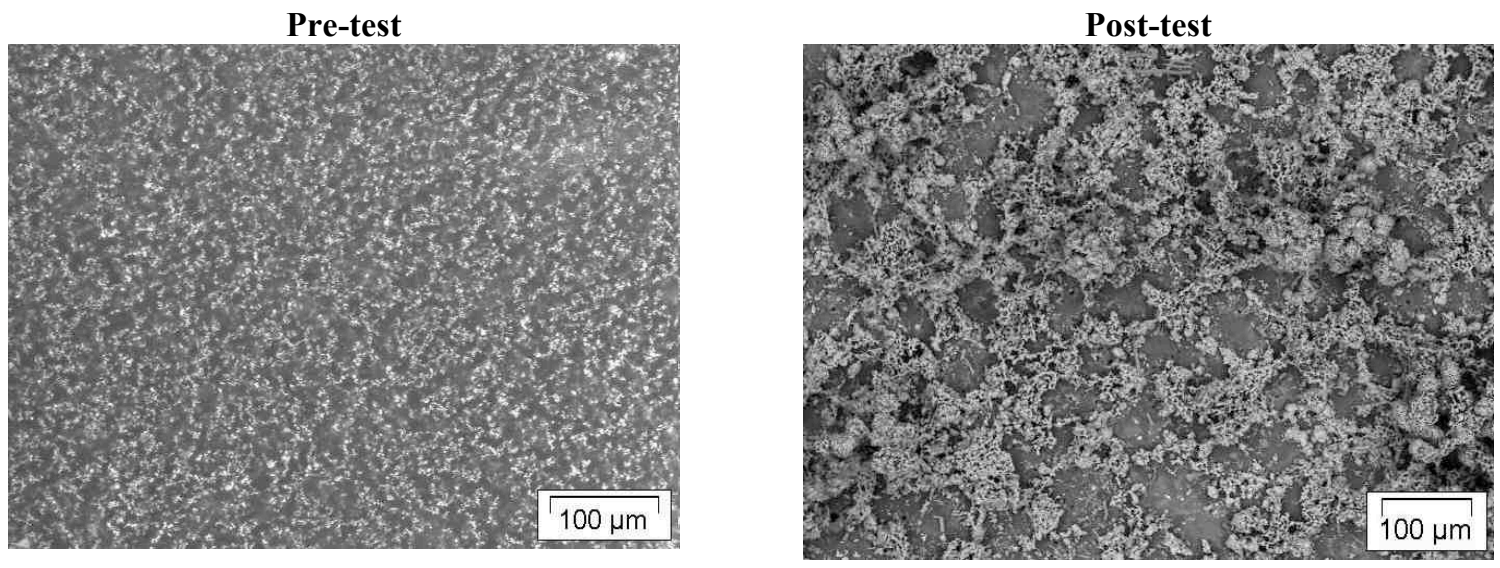

a) SEM
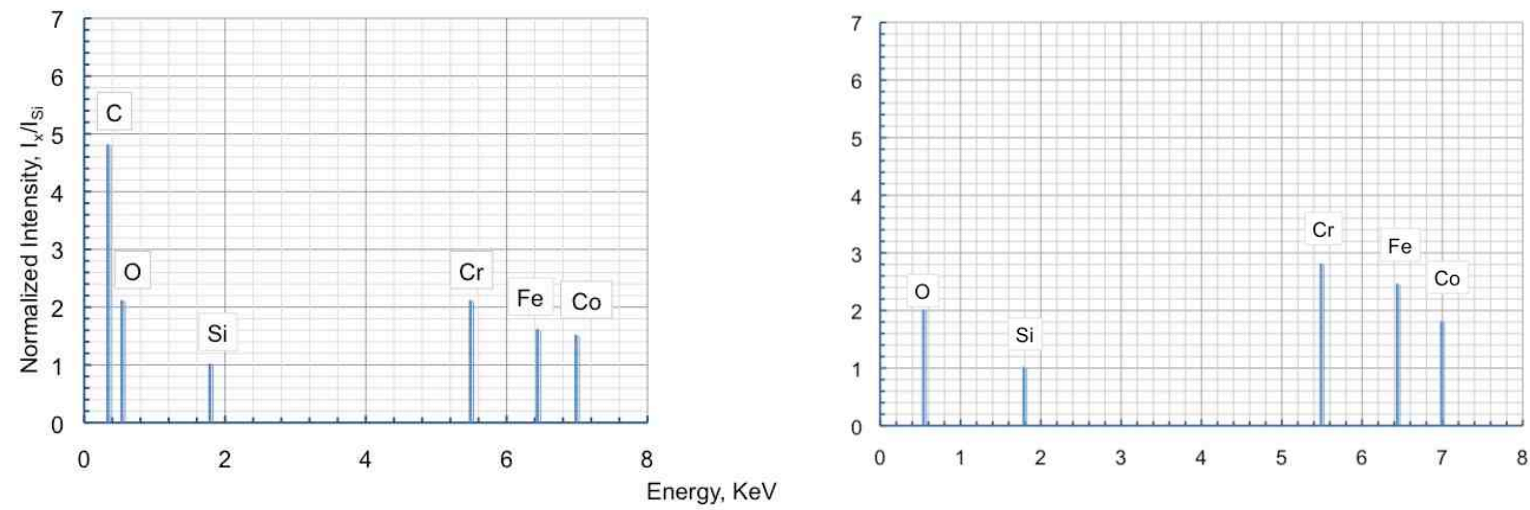

b) X-ray florescence analysis, 3-minute exposure at $T_{W}=1617 \mathrm{~K}$

Figure 9. Effect of arc-jet exposure on surface morphology and chemistry of the CC-2 coating.

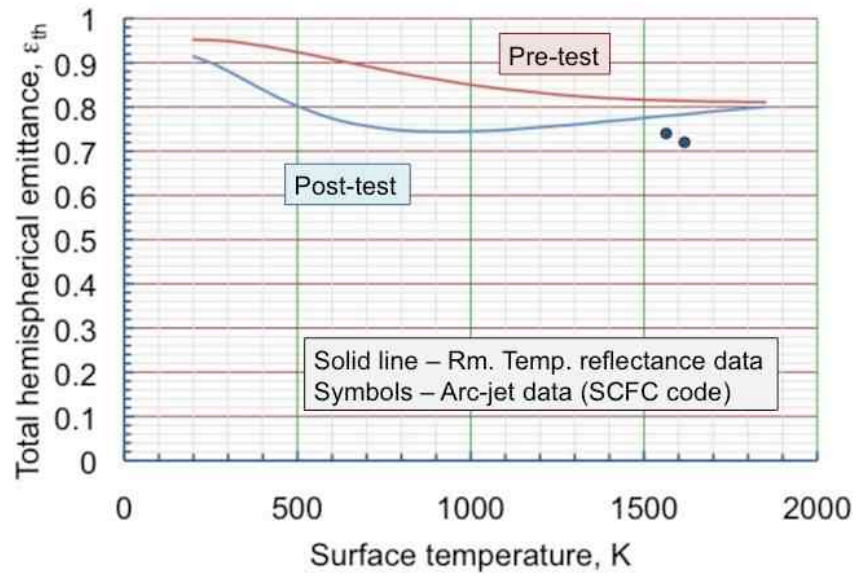

Figure 10. Effect of arc-jet exposure on the emittance of the CC-2 coating.

Calculated pre- and post-test total hemispherical emittance (solid lines), using the reflectance data, are compared with the values (symbols) used in the SCFC code to predict the atom recombination coefficients, Figure 10. 
The total hemispherical emittance derived from the arc-jet data are lower than the values obtained from the room temperature reflectance data (approximately 0.73 compared to 0.79 ).

The atom recombination coefficients for both oxygen and nitrogen for the CC-2 coating are plotted in Figure 11. The high temperature coefficients $\left(\mathrm{T}_{\mathrm{W}}>1256 \mathrm{~K}\right)$ were obtained using the arc-jet data and SCFC code. ${ }^{11}$ This code assumes frozen chemistry and incorporates Goulard's theory as part of the nozzle program. Coefficients at $\mathrm{T}_{\mathrm{W}}<$ $1256 \mathrm{~K}$ were obtained from side-arm-reactor data using the basic diffusion equation with appropriate boundary conditions at the tube interfaces. ${ }^{10}$ Included on the plot are the corresponding Arrhenius expressions for the data from room temperature to $1700 \mathrm{~K}\left(2600^{\circ} \mathrm{F}\right)$.

Nitrogen:

$$
\begin{aligned}
& \mathrm{T}_{\mathrm{W}}<760 \mathrm{~K} \\
& \gamma_{\mathrm{N}}=0.0032 \\
& \mathrm{~T}_{\mathrm{W}}>760 \mathrm{~K} \\
& \quad \gamma_{\mathrm{N}}=33.0 \varepsilon^{-7013 / \mathrm{T \omega}}
\end{aligned}
$$

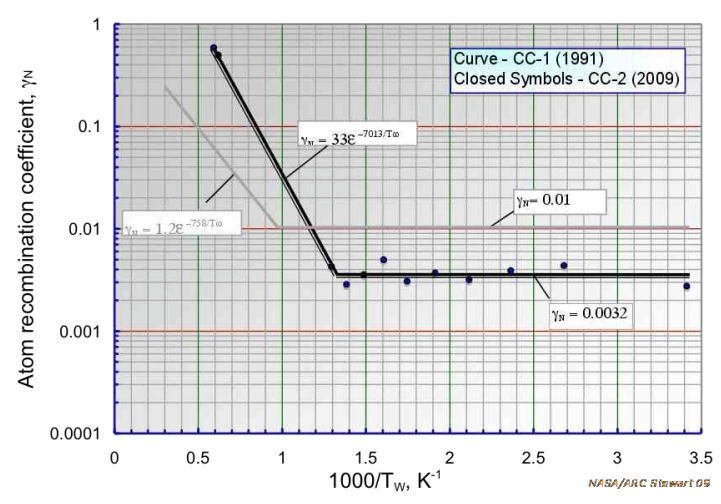

a) Nitrogen
Oxygen:

$$
\begin{gathered}
\mathrm{T}_{\mathrm{W}}<667 \mathrm{~K} \\
\gamma_{\mathrm{O}}=0.0045 \\
\mathrm{~T}_{\mathrm{W}}>760 \mathrm{~K} \\
\gamma_{\mathrm{O}}=12.0 \varepsilon^{-5263 / \mathrm{T \omega}}
\end{gathered}
$$

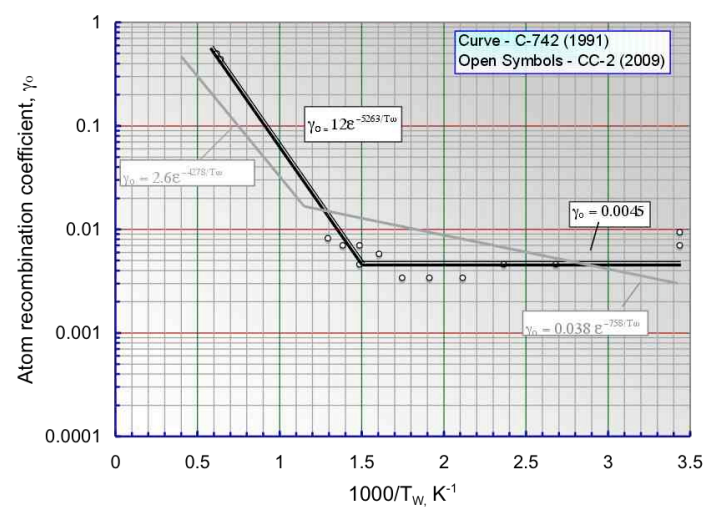

b) Oxygen

\section{Figure 11. Atom recombination coefficients for the CC-2 coating.}

The data indicate that the coefficients for both nitrogen and oxygen atom recombination for the CC-2 coating are typically lower at surface temperatures below roughly $700 \mathrm{~K}$ and increase most rapidly at higher temperatures than the original CC-1 coating used on the early shuttle flight experiments reported at the Williamsburg Symposium in $1993 .^{5}$

\section{Computational Simulations}

Computational analyses of the arc-jet tests were performed through simulation of nonequilibrium expanding flow in the arc-jet nozzle, supersonic jet, test box, and simulation of the flow around the test articles. For all CFD calculations, the DPLR code, ${ }^{13,14}$ a code developed at NASA Ames, is used. For the present CFD simulations, the axisymmetric and 3-D Navier-Stokes equations, supplemented with the equations accounting for nonequilibrium kinetic processes, are used in the formulation. The present calculations employ a 6-species air model $\left(\mathrm{N}_{2} \mathrm{O}_{2}, \mathrm{NO}, \mathrm{N}\right.$, $\mathrm{O}, \mathrm{Ar}$ ) for arc-jet flow, and the thermal state of the gas is described by two temperatures: translational-rotational and vibrational-electronic, within the framework of Park's two-temperature model. ${ }^{15}$ The calculations were made by defining the flow properties at the sonic point in the nozzle and then processing downstream across the bow shock wave and over the test article surface. Computations are then used to predict the surface properties of the flat-plate test article, which was exposed at an angle-of-attack of $30^{\circ}$ to the high-energy arc-jet flow. The DPLR solution incorporated the surface properties (atom recombination coefficients and emissivity values) calculated from the data obtained in Phase II study. 
Figure 12 shows the experimental infrared temperature data for the plug used on the flat-plate model. The temperature rise in the catalytic portion of the plug (CC-2 coating) with respect to that of the RCG coated section is clearly observed. Although the spacial orientation of IR camera with respect to the plug is not known accurately, the line on the figure approximately corresponds to the centerline of the plug on the flat-plate model. Increase in the surface temperature on the catalytic portion of the plug is clearly observed.

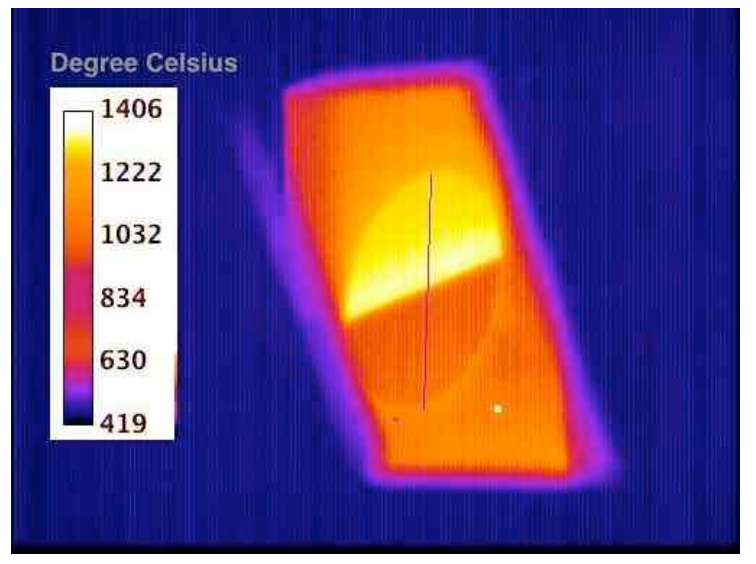

Figure 12. Experimental IR temperature data for the flat-plate plug, AHF 285 Run 2.

Computational simulation results are now presented for the flat plate model. Figure 13 shows the computational surface grid used for the flat-plate model and location of the RCG and CC-2 coatings.

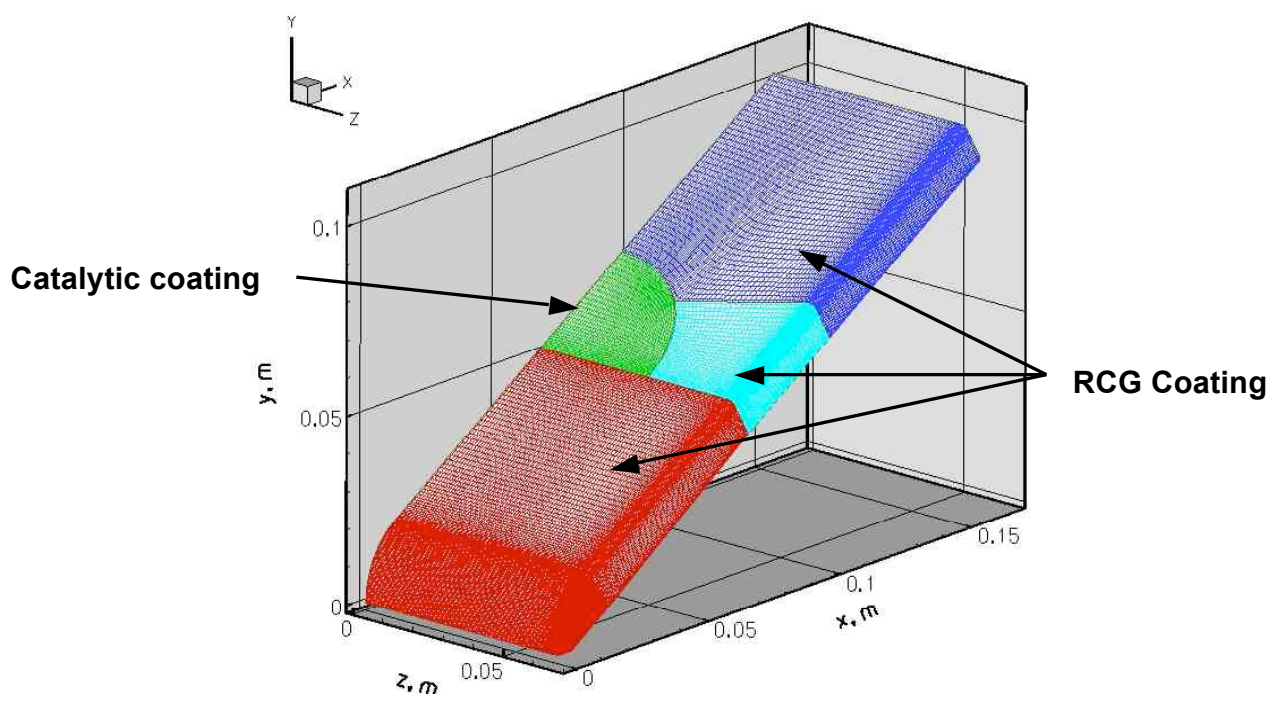

Figure 13. Computational surface grid used for the flat-plate model in DLPR simulation $\left(R_{N}=0.022 \mathrm{~m}\right)$.

The predicted surface contours of pressure, temperature and shear of the flat plate model and corresponding centerline profiles are shown in Figure 14. The predicted centerline temperature profile calculated from DLPR agreed reasonably well with he measured surface temperatures taken from the flat plate. Finally, Figure 14c indicates that the computed shear load on the flat plate plug was roughly 35-40 Pa, which is close to the value predicted for the laminar flight case, but roughly half that predicted for the turbulent flight case. 

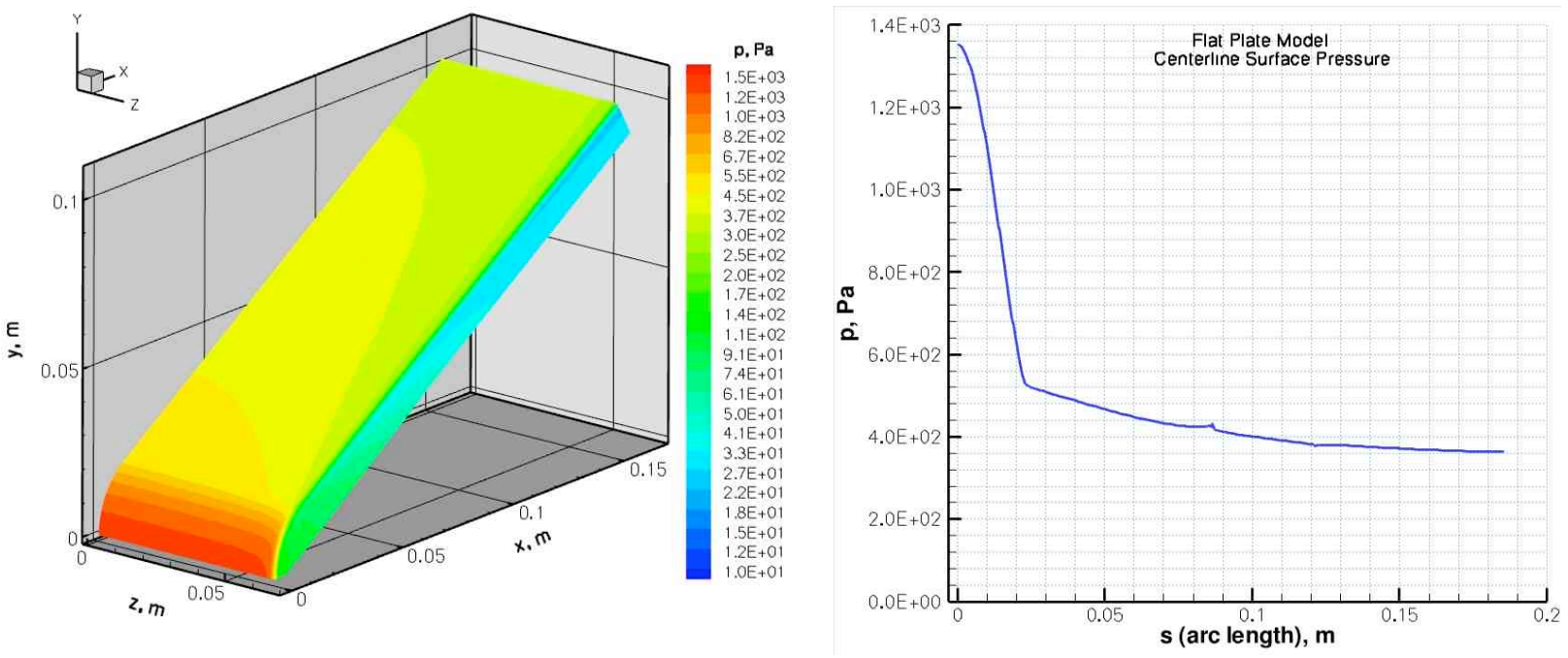

(a) Pressure
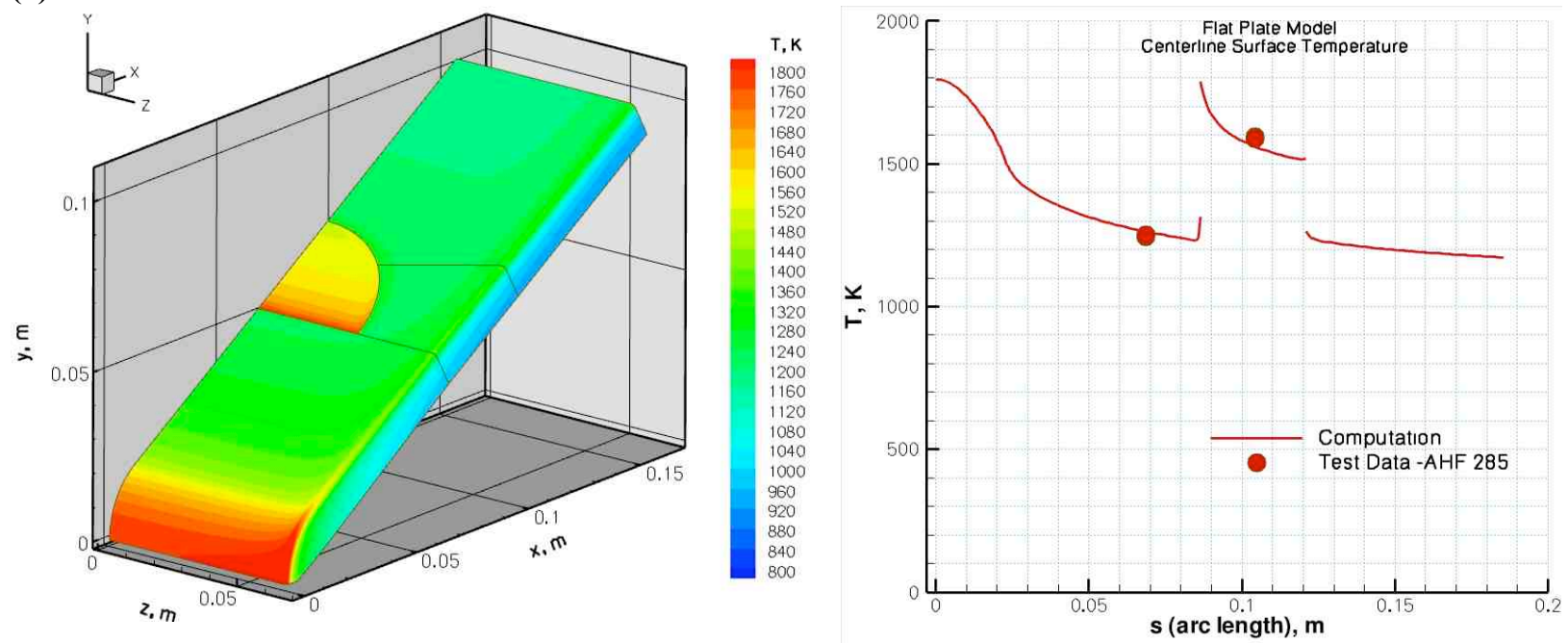

(b) Temperature
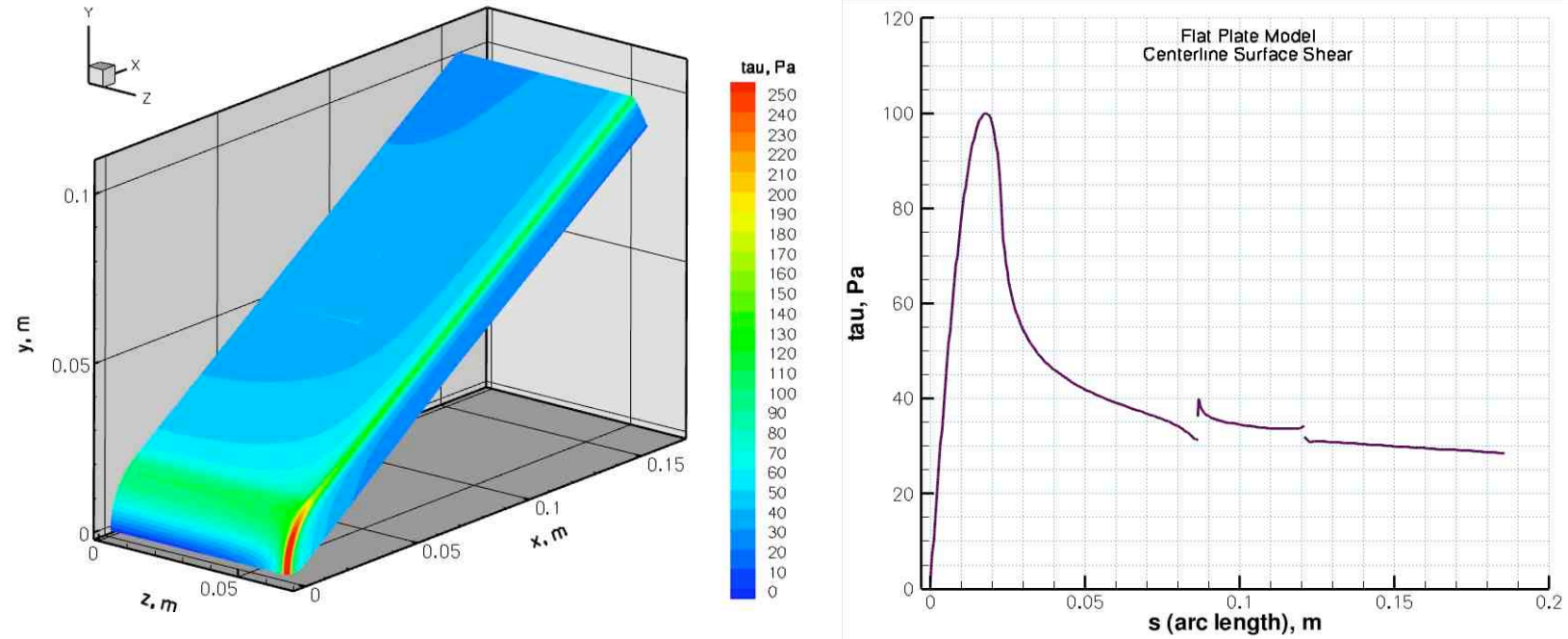

(c) Shear

Figure 14. Predicted surface contours and centerline profile over the flat plate. AHF 24-inch nozzle flow: $\mathbf{H}_{0}$ $=13.5 \mathrm{MJ} / \mathrm{kg}, \mathrm{P}_{\mathrm{CH}}=1.72 \mathrm{~atm}$. 


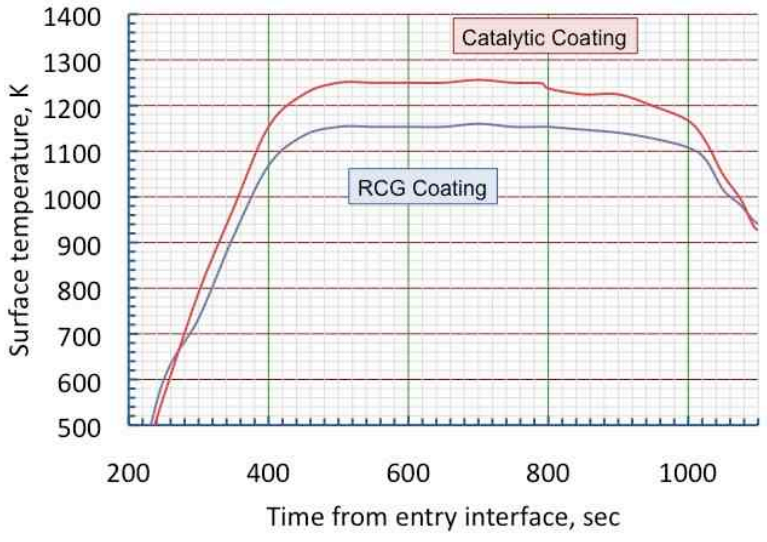

(a) STS-5, $x / L=0.82(C C-1)$

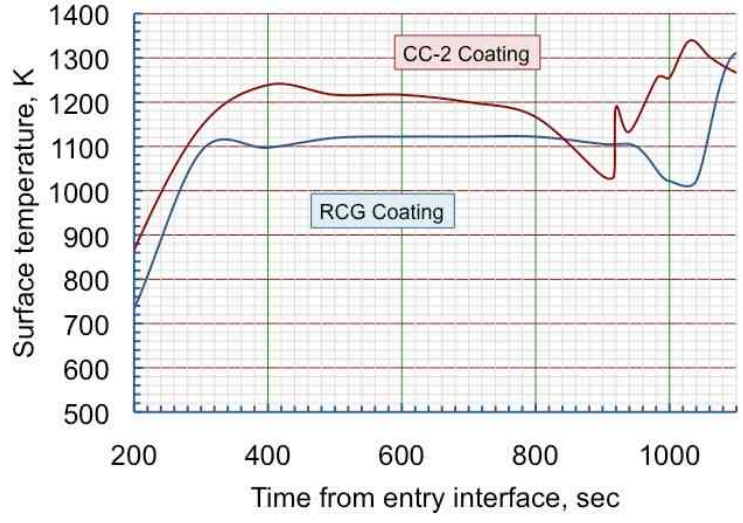

(b) STS-128, $\mathrm{x} / \mathrm{L}=\mathbf{0 . 8 0}(\mathrm{CC}-2)$

Figure 15. Effect of the $\mathrm{CC}-1$ and $\mathrm{CC}-2$ coatings on heating over lower wing surface during shuttle Earth entry.

\section{Shuttle Flight Data}

Experimental data taken from the lower surface of the wing during STS-128 Earth entry are compared with previous data obtained from the same general area of the lower surface of the wing during the STS-5 flight. $5,6,16$ During the portion of the Earth entry in which the boundary-layer flow over the wing was laminar, the increase in the surface temperature as a result of the application of the CC-2 coating was roughly $360 \mathrm{~K}\left(200^{\circ} \mathrm{F}\right)$ which is similar to the increased temperature observed during flight STS-5. ${ }^{2,5}$ However, the data indicates that transition to turbulent flow over the wing on STS-128 occurred earlier in the flight (approx. 150 seconds) than during the STS-5 flight. In Reference 6, a detailed discussion of the STS-128 flight data is given relative to on-set of transition to turbulence and other flow field characteristics affected by the protuberance and catalytic coating applied downstream from it. The CC-2 coating remained on the tile after the flight.

\section{Summary}

Results from the screening and surface characterization studies conducted the NASA Ames Research Center AHF showed:

- Elemental analysis indicates that candidate coating 15E (reacted oxides similar to C-742) was not chemically stable after arc-jet exposure to $1589 \mathrm{~K}$ for nine minutes. It should be noted that the $\mathrm{CC}-1$ coating was never used in a flight experiment above $1422 \mathrm{~K}\left(2100^{\circ} \mathrm{F}\right)$; therefore was not required to be stable above $1478 \mathrm{~K}$ $\left(2200^{\circ} \mathrm{F}\right)$.

- Elemental analysis indicates that $15 \mathrm{~B}$ (CC-2 coating) was chemically stable during a nine-minute exposure at a surface temperature of $1589 \mathrm{~K}\left(2400^{\circ} \mathrm{F}\right)$ in the high-enthalpy hypersonic arc-jet stream. Therefore, it was chosen as the coating for the flight experiment.

- Total hemispherical emittance of the CC-2 coating at $1589 \mathrm{~K}\left(2400{ }^{\circ} \mathrm{F}\right)$ is somewhat lower than $\mathrm{RCG}\left(\varepsilon_{\mathrm{th}}=\right.$ 0.85). Emittance calculated from post-test reflectance data was 0.78 for $\mathrm{T}_{\mathrm{W}}=1589 \mathrm{~K}$.

- Atom recombination coefficients have been calculated from both arc-jet test and side-arm-reactor data. Arrhenius expressions developed for surface temperatures from room temperature to $1700 \mathrm{~K}$ showed that in general the coefficients for CC-2 are higher than the CC-1 coating above $1000 \mathrm{~K}$.

- No noticeable recession was measured on the LI-900 blunt cone after a stagnation test at $1700 \mathrm{~K}$ for an exposure of 3 minutes.

- Flight performance of the CC-2 coating was very similar to the CC-1 coating used for the experiments on STS-5. 


\section{Acknowledgments}

The authors would like to thank the ceramic laboratory and in particular Jeff Figone and Matt Switzer for their contributions to the development of test articles and coating application for this study; Mike Gusman, Jose Garcia Chavez, and Jerry Ridge for their help in the development of the reacted oxides (coating 15E) and providing pre and post-test surface characterization data from the test articles. The authors would also like to acknowledge the support from NASA Ames Space Technology Division through contract NNA04BC25C to ELORET Corporation.

\section{References}

${ }^{1}$ Stewart, D. A., Rakich, J. V., and Lanfranco, M. J., "Catalytic Surface Effects Experiment on Space Shuttle,” AIAA Paper 81-0143, Palo Alto, CA, 1981.

${ }^{2}$ Stewart, D. A., Rakich, J. V., and Lanfranco, M. J., "Results of a Flight Experiment on the Catalytic Efficiency of the Space Shuttle Heat Shield," AIAA Paper 82-0944, St. Louis, MO, 1982.

${ }^{3}$ Stewart, D. A., Rakich, J. V., and Lanfranco, M. J., "Catalytic Surface Effect Space Shuttle Thermal Protection System During Earth Entry of Flights STS-2through STS-5," Shuttle Performance: Lessons Learned, NASA CP2283, part 2, 1983.

${ }^{4}$ Stewart, D. A., "Catalytic Surface Effects Experiment for Space Shuttle," Orbiter Experiments (OEX) Aerothermodynamics Symposium, Williamsburg, VA, April 1993, pg. 171.

${ }^{5}$ Stewart, D. A., "Flight Experiment Demonstrating the Effect of Surface Catalysis on the Heating Distribution Over the Space Shuttle Heat Shield," Orbiter Experiments (OEX) Aerothermodynamics Symposium, Williamsburg, VA, April, 1993, pg. 677-701.

${ }^{6}$ Anderson, B. P., Campbell, C. H., Saucedo, L. A,, Gerald, R. K., and Karen, B. T., "Boundary Layer Transition Flight Experiment Overview and In-Situ Measurements," AIAA Paper 2010-240, Orlando, FL, January 2010.

${ }^{7}$ Ames Research Facilities Summary, NASA Ames Research Center, Moffett Field, CA 1974.

${ }^{8}$ Stewart, D. A., Gökçen, T., and Chen, Y. K., "Characterization of Hypersonic Flows in the AHF and IHF NASA Ames ArcJet Facilities,” AIAA Paper 2009-4237, San Antonio, TX, June 2009.

${ }^{9}$ Pallix, J. B., and Copeland, R. A., "Measurement of Catalytic Recombination Coefficients on Quartz Using Laser-Induced Fluorescence," Journal of Thermophysics and Heat Transfer, Vol. 10, No. 2, 1996, pp. 224-233.

${ }^{10}$ Marschall, J., "Experimental Determination of Oxygen and Nitrogen Recombination Coefficients at Elevated Temperatures Using Laser-Induced Fluorescence,” National Heat Transfer Conference, Baltimore, Md., AIAA Paper 97-3879, August 1997.

${ }^{11}$ Stewart, D. A., "Surface Catalytic and Characterization of Proposed Candidate TPS for Access-to-Space Vehicles," NASA TM-112206, July 1997.

${ }^{12}$ Lees, L., "Laminar Heat Transfer Over Blunt-Nose Bodies at Hypersonic Flight Speeds," Jet Propulsion, Vol. 26, No. 4, April 1956.

${ }^{13}$ Wright, M. J., Candler, G. V., and Bose, D., "Data-Parallel Line Relaxation Method for the Navier-Stokes Equations," AIAA Journal, Vol. 36, No. 9, 1998, pp. 1603-1609.

${ }^{14}$ Wright, M. J., “Data-Parallel Line Relaxation Code, DPLR Version 3.05,” Private Communication, June 2006.

${ }^{15}$ Park, C., "Assessment of a Two-Temperature Kinetic Model for Dissociating and Weakly Ionizing Nitrogen,” Journal of Thermophysics and Heat Transfer, Vol. 2, No. 1, 1988, pp. 8-16.

${ }^{16}$ Campbell, C. H., "STS-128 preliminary surface temperature data taken from adjacent tiles coated with RCG and CC-2 coatings located on the lower surface of the Orbiter's wing," Private Communication, October 2009. 